Dept. Path \& Lab Medicine, BC Cancer Agency, 675 W10th Avenue, Vancouver V6R 3A6, Canada, saparicio@bccrc.ca

Fariba Behbod,

Department of Pathology, University of Kansas Medical Center, 3901 Rainbow Blvd, WHE 1005B, Kansas City, KS 66160, fbehbod@kumc.edu

\section{Mohamed Bentires-Alj,}

Department of Biomedicine, University of Basel, University Hospital Basel, Basel, Switzerland

Lab 306, Hebelstrasse 20, CH-4031 Basel, Switzerland, m.bentires-alj@unibas.ch

\section{Cathrin Brisken,}

ISREC - Swiss Institute for Experimental Cancer Research, School of Life Sciences, Ecole Polytechnique Fédérale de Lausanne (EPFL), SV2.832 Station 19, CH-1015 Lausanne, Switzerland. Phone +41 (0)21 69307 81, Sec: +41 (0)21 69307 62, Fax +41 (0)2169307 40, cathrin.brisken@epfl.ch

Carol J. Bult,

The Jackson Laboratory, Bar Harbor, Maine 04609, carol.bult@jax.org

\section{Shirong Cai,}

Department of Experimental Radiation Oncology, The University of Texas MD Anderson Cancer Center, Houston, TX 77030, SCai1@mdanderson.org

\section{Robert B. Clarke,}

Breast Cancer Now Research Unit, Division of Molecular and Clinical Cancer Studies, Manchester Cancer Research Centre, University of Manchester, Wilmslow Road, Manchester, M214QL, UK, Robert.clarke@manchester.ac.uk

\section{Heidi Dowst,}

Dan L. Duncan Cancer Center, Baylor College of Medicine, Houston TX 77030, dowst@bcm.edu

\section{Matthew J. Ellis,}

The Lester and Sue Smith Breast Center, Departments of Molecular and Cellular Biology and Radiology, Baylor College of Medicine, Houston TX 77030, Matthew.Ellis@bcm.edu

\section{Eva Gonzalez-Suarez,}

Cancer Epigenetics and Biology Program, PEBC, Bellvitge Institute for Biomedical Research, IDIBELL, Av.Gran Via de L'Hospitalet, 199 - 203, 08908 L'Hospitalet de Llobregat, Barcelona, Spain, egsuarez@idibell.cat, Phone: +34 932607347, Fax: +34 932607139

\section{Richard D. Iggo,}

INSERM U1218, Bergonié Cancer Institute, 229 cours de l'Argonne, 33076 Bordeaux, France, r.iggo@bordeaux.unicancer.fr

\section{Peter Kabos,}

Division of Medical Oncology, Department of Medicine, University of Colorado Anschutz Medical Campus, Aurora, CO 80045, Peter.Kabos@ucdenver.edu

\section{Shunqiang Li,}


Department of Internal Medicine, Washington University, St. Louis, MO 63130, Tel. 314-747-9311, shunqiangli@wustl.edu

\section{Geoffrey J. Lindeman,}

Stem Cells and Cancer Division, The Walter and Eliza Hall Institute of Medical Research, 1G Royal Parade, Parkville, VIC 3052, Australia

Department of Medicine, The University of Melbourne, Parkville, VIC 3010, Australia

Familial Cancer Centre, The Royal Melbourne Hospital and Peter MacCallum Cancer Centre.

Grattan St, Parkville, VIC 3050, Australia, lindeman@wehi.EDU.AU

\section{Elisabetta Marangoni,}

Translational Research Department, Institut Curie, 26, rue d'Ulm, 75005 Paris - FRANCE, Elisabetta.Marangoni@curie.fr

\section{Aaron McCoy,}

Department of Experimental Radiation Oncology, The University of Texas MD Anderson Cancer Center, Houston, TX 77030, AMMcCoy@mdanderson.org

\section{Funda Meric-Bernstam, MD,}

Departments of Investigational Cancer Therapeutics and Breast Surgical Oncology, UT M. D. Anderson Cancer Center, Houston TX 77030, fmeric@mdanderson.org

\section{Helen Piwnica-Worms,}

Department of Experimental Radiation Oncology, The University of Texas MD Anderson Cancer Center, Houston, TX 77030, hpiwnica-worms@mdanderson.org

\section{Marie-France Poupon,}

Founder and Scientific Advisor, Xentech SA, Genepole, 4 rue Pierre Fontaine, 91000 Evry, France, mariefrancepoupon@gmail.com

\section{Jorge Reis-Filho,}

Director of Experimental Pathology, Department of Pathology, Memorial Sloan Kettering Cancer Center, New York, NY

Affiliate Member, Human Oncology and Pathogenesis Program, and Center for Computational Biology, Memorial Sloan Kettering Cancer Center, New York, NY, reisfilj@mskcc.org

\section{Carol A. Sartorius,}

Department of Pathology, University of Colorado Anschutz Medical Campus, Aurora, CO 80045, Carol.Sartorius@ucdenver.edu

\section{Valentina Scabia,}

ISREC - Swiss Institute for Experimental Cancer Research, School of Life Sciences, Ecole Polytechnique Fédérale de Lausanne (EPFL), SV2.832 Station 19, CH-1015 Lausanne, Switzerland, valentina.scabia@epfl.ch

\section{George Sflomos,}

ISREC - Swiss Institute for Experimental Cancer Research, School of Life Sciences, Ecole Polytechnique Fédérale de Lausanne (EPFL), SV2.832 Station 19, CH-1015 Lausanne, Switzerland. georgios.sflomos@epfl.ch 
Yizheng Tu,

Department of Experimental Radiation Oncology, The University of Texas MD Anderson Cancer Center, Houston, TX 77030, YTu1@mdanderson.org

François Vaillant,

Stem Cells and Cancer Division, The Walter and Eliza Hall Institute of Medical Research, 1G Royal Parade, Parkville, VIC 3052, Australia

Department of Medical Biology, The University of Melbourne, Parkville, VIC 3010, Australia, vaillant@wehi.edu.au

Jane E. Visvader,

Stem Cells and Cancer Division, The Walter and Eliza Hall Institute of Medical Research, 1G Royal Parade, Parkville, VIC 3052, Australia

Department of Medical Biology, The University of Melbourne, Parkville, VIC 3010, Australia, visvader@wehi.EDU.AU

Alana Welm,

Huntsman Cancer Institute, University of Utah, 2000 Circle of Hope, Salt Lake City, UT 84112 , Alana.Welm@hci.utah.edu

Max S. Wicha, and

Madeline and Sidney Forbes Professor of Oncology, Director, Forbes Institute for Cancer Discovery, NCRC 26-335S, SPC 2800, 2800 Plymouth Rd., Ann Arbor, MI 48109-2800, Phone: (734)763-1744, Fax: (734)764-1228, http://www.med.umich.edu/wicha-lab/index.html, mwicha@med.umich.edu

\section{Michael T. Lewis ${ }^{*}$}

The Lester and Sue Smith Breast Center, Departments of Molecular and Cellular Biology and Radiology, Baylor College of Medicine, Houston TX 77030, mtlewis@bcm.edu, TEL: 713-798-3296, FAX: 713-798-1659

\section{Abstract}

Patient-derived xenograft (PDX) models of a growing spectrum of cancers are rapidly supplanting long-established traditional cell lines as preferred models for conducting basic and translational pre-clinical research. In breast cancer, to complement the now curated collection of approximately 45 long-established human breast cancer cell lines, a newly formed consortium of academic laboratories, currently from Europe, Australia, and North America, herein summarizes data on over 500 stably transplantable PDX models representing all three clinical subtypes of breast cancer (ER+, HER2+, and "Triple-negative" (TNBC)). Many of these models are wellcharacterized with respect to genomic, transcriptomic, and proteomic features, metastatic behavior, and treatment response to a variety of standard-of-care and experimental therapeutics. These stably transplantable PDX lines are generally available for dissemination to laboratories conducting translational research, and contact information for each collection is provided. This review summarizes current experiences related to PDX generation across participating groups, efforts to develop data standards for annotation and dissemination of patient clinical information that does not compromise patient privacy, efforts to develop complementary data standards for annotation of PDX characteristics and biology, and progress toward "credentialing" of PDX models as 
surrogates to represent individual patients for use in pre-clinical and co-clinical translational research. In addition, this review highlights important unresolved questions, as well as current limitations, that have hampered more efficient generation of PDX lines and more rapid adoption of PDX use in translational breast cancer research.

\section{Keywords}

Patient-derived xenograft; breast cancer; immunocompromised/immunodeficient mice; translational research; PDX consortium

\section{Introduction}

Human breast cancer is now recognized, not as a single disease, but as a heterogeneous collection of diseases characterized by diversity in histology, genomic alterations, gene expression, metastatic behavior, and treatment responses [1-7]. In addition to heterogeneity between tumors across the patient population (or between two primary tumors in a single patient), recent data have also demonstrated considerable intra-tumoral heterogeneity (that is between cells within a single tumor, and between a primary tumor and its associated metastases in a single patient). This degree of heterogeneity is a significant hindrance for making effective treatment decisions, and begs for the development of personalized approaches to therapy based on the specific biology of an individual, and their unique tumor [8]. With respect to basic and translational research, the existence of disease heterogeneity, both within and among breast cancers, also presents significant challenges to generation and use of relevant pre-clinical models that represent the full spectrum of breast disease $[9,10]$.

If our ultimate goal is to offer each breast cancer patient an individualized treatment plan tailored to her (or his) specific tumor and progression status, it will be essential to define fully the molecular and cellular heterogeneity within and among the tumor subtypes, and indeed within each patient's tumor, and relate these differences to clinical behavior. Specifically, these characteristics need to be linked to metastatic behavior and differential treatment response, the lethal aspects of breast cancer, in order to 'personalize' effective treatment. Patient-derived xenograft (PDX) models hold high promise as a discovery and validation platform, particularly as a unified collection across multiple institutions, for meeting this daunting challenge.

\section{I.A. The Problem of Inter-tumoral Heterogeneity}

Clinically, breast cancers are divided essentially into three subtypes: 1) those that express the estrogen receptor alpha $(\mathrm{ER}+)$ (which typically also express the progesterone receptor (PR $+)$ ), 2) those that are genomically amplified for and/or overexpress ERBB2 (HER2+) (encoding a member of the epidermal growth factor receptor family of tyrosine kinases), and 3) those that express none of these three markers (termed "triple negative" breast cancer (TNBC) ) [1-4]. While clinically useful, molecularly targeted therapies exist for ER+ breast cancer (e.g. Selective Estrogen Receptor Modulators (SERMs), aromatase inhibitors (AI), Selective Estrogen Receptor Downregulators (SERDs)) [11] and HER2+ breast cancer (e.g. Trastuzumab, Lapatinib) [12], there are currently no approved targeted therapies for TNBC. 
Current treatment of TNBC entails surgery coupled with radio- and/or chemotherapy (most often taxane- or anthracycline-based, with platinum-based agents emerging as promising first line therapies (e.g. [13])) in either the neoadjuvant (before surgery) or adjuvant (after surgery) settings.

With the development of RNA expression array technology over 15 years ago, more detailed molecular classification of breast cancer became possible. In a landmark analysis of global RNA expression, five intrinsic molecular subtypes of breast cancer were proposed: luminal A (ER+, with signatures consistent with lower proliferation rates that can be correlated with comparatively lower Ki67 immunostaining), luminal B (ER+, with signatures consistent with elevated proliferation that can be correlated with comparatively higher Ki67 immunostaining), basal-like (predominantly TNBC), HER2-enriched, and normal breastlike. Each molecular subtype correlated with unique clinical behavior including differences in overall survival, patterns of metastasis, and response to treatment $[5,4,7,6]$. Subsequently, the claudin-low subtype was identified. Claudin-low tumors are predominantly TNBC, with comparatively low expression of Claudins 3,4 , and 7 [14], enrichment for mesenchymal markers [5], and enrichment of a stem cell-like $\left(\mathrm{CD} 44^{+} / \mathrm{CD} 24^{\mathrm{Neg} / \mathrm{Low}}\right)$ gene expression signature $[15,5,16]$.

Within the last 5 years, detailed genomic analysis of breast cancers by several groups including the ICGC, TCGA and METABRIC consortia [17-21], have shown that additional molecular subytypes associated with distinct survival trends can be distinguished, such as the $4 \%$ of breast cancers that are ER+ with complex amplifications around 11q [18] and those showing differential survival associated with PIK3CA mutation [22,23]. TNBC has been found to constitute at least two and perhaps more, distinct biological subgroups based on integrated genomics [24] - a genomically quiescent, PIK3CA mutation-containing, intermediate-good prognosis group (about $25 \%$ of TNBC), that group more with ER+ cancers (a proportion express AR) of the IntClust 4 subtype and the remainder which are almost universally mutated for TP53, have unstable genomes, a basal epithelial gene expression signature type and poor prognosis with early relapse. Some TNBC gene expression studies have suggested TNBC could be subdivided further into four or more distinct subgroups [25-28]

\section{I.B. The Problem of Intra-tumoral Heterogeneity}

Pathologists have long appreciated heterogeneity in both histology and biomarker expression within a given tumor. For example, in ER+ tumors, not all cells express the receptor. Clinically, ER+ breast cancers can be qualified as such even if only $1 \%$ of cells express detectable levels of ER protein, though some low-expressing tumors may behave as ERnegative tumors in response to targeted therapies [29,30]. Similarly, HER2+ tumors can show regional variation in expression by immunohistochemistry and copy number per cell by fluorescence in situ hybridization, with positivity clinically defined as $10 \%$ of cells positive (CAP Guidelines) [31,32,12].

Although clonal structure has been appreciated as a defining feature of cancers for several decades [33], methods for understanding clonal structure in solid epithelial cancers have only recently advanced. Until very recently, the existence of genetically distinct 
subpopulations within tumors, and within metastatic cell populations, was not appreciated (see [34-36] and references therein). With the development of computational approaches to infer clonal structure from bulk tumor sequence data (eg. [37-40,20,41]), as well as methods for single cell DNA and RNA sequencing (eg [42-48]), breast cancers are now known to contain multiple genetically distinct subclones [49,50]. Primary TNBC have been shown to be clonally diverse among patients with the same stage/grade of tumour. Further work suggests that distinct subclones may, in some instances, be capable of interacting with one another to maintain homeostatic balance between clonal populations, and promote tumor growth [51].

\section{I.C. Patient-derived breast cancer xenografts as potentially powerful tools for pre-clinical and translational research}

In theory, if PDX models can represent the full spectrum of heterogeneity of breast cancers in the population, and can be fully "credentialed" to retain the critical molecular and biological properties of their tumor of origin, these models would then represent exceptionally powerful tools for translational research. In large part, their potential power lies in the fact that they have been demonstrated to be biologically stable (generally) and, as such, are renewable indefinitely. Thus, PDX models can be interrogated in greater depth both biologically and molecularly than any given patient sample is likely to be (unless very large). Further, PDX can be challenged with as many candidate therapeutics, or treatment regimens, as desired in a relatively short time frame versus what can be accomplished in the clinic. In contrast, the tumor of origin (and patient), can only be challenged sequentially with one treatment regimen at a time, and only at significant risk of potentially lethal or debilitating side effects.

Herein, we garner the collective experience of a new international consortium of breast cancer PDX developers to review the state-of-the-art in the field, to outline open questions remaining to be addressed, and to summarize the utility, limitations, and future promise of breast cancer PDX models in translational research.

\section{The State-Of-The-Art In Breast Cancer PDX Modeling}

\section{II.A. Patient-derived xenografts (PDX) models that represent all three clinically-defined breast cancer subtypes have been established by various groups}

In addition to the need to represent the heterogeneity of breast cancers as completely and accurately as possible, breast cancer is heavily influenced by the tumor microenvironment, making in vivo models desirable for studying complex processes like tumor metastasis and response to therapy. Efforts to establish stably transplantable xenograft lines directly from patients into immunocompromised mice have been going on for decades. Unfortunately, while initial take rates (i.e. initial outgrowths directly from patients) can be quite high ( 40 90\%) [52-54], success rates of generating stably transplantable xenografts (generally, but not uniformly, defined as PDX with the ability to be serially transplanted $\geq 3$ passages in mice (variously termed "passage 2 (P2)", with P0 being the initial transplant from mouse to human, or "transplant generation 3 (TG3)") (Tables 1 and 3) from early efforts were comparatively low, in the $10 \%$ range overall $[52,55-64,53]$. As a consequence, few stably 
transplantable models were established for dissemination to the research community from this earlier work.

More recently, with newly-developed immunodeficient host mouse models [65], and modified transplantation conditions, overall stable take rates have now reached in excess of $20 \%$ on a routine basis (e.g. $[66,54,67-73,37,74,75,13])$. Further, a concerted effort is being made to develop these collections of stable, well-characterized, PDX lines as qualitycontrolled, renewable tissue resources for distribution to the research community. A list of PDX collections available for dissemination, along with the patient/tumor population characteristics from which they were derived, is presented in Table 1; contact information for each collection is listed in Table 2. In addition to collections resident in academic institutions, several commercial entities retain PDX collections of their own, consisting of PDX lines either generated in house, or licensed from academic institutions. These commercial collections are not discussed here.

Taken in aggregate, the academic institutions participating in this consortium have developed 537 individual PDX lines, representing over 500 unique patients. With respect to clinical subtypes represented, $56 \%$ of patients yielding PDX lines had TNBC, with $36 \%$ of patients having ER+ cancer. Patients with HER2+ breast cancer are significantly underrepresented in these collections, representing only $8 \%$ of patients yielding PDX models, due to the combined facts that they represent only $\sim 10-15 \%$ of all breast cancers, and show a lower overall take rate than TNBC (which also accounts for 10-15\% of all breast cancers, but show a higher take rate) (Table 3).

Given the clinical observation that patients of different ethnic and racial backgrounds can have distinct treatment responses and disease outcomes, an important consideration is the ethnic and racial distribution of patients yielding PDX lines. In general, the diversity of PDX lines in a given collection represents the diversity in the associated patient population from which they were derived. While Caucasian women are most heavily represented across these collections, there are now a number of PDX lines representing African American and Hispanic women (Table 1). However, only a few PDX lines represent patients of Asian or African descent, and no PDX lines represent indigenous populations (e.g. Native Americans), or male breast cancer patients, among others.

Of note, the PDX lines representing Continental African patients from Ghana (Wicha et al, unpublished) were developed using primary tumor samples that had been viably frozen and shipped on dry ice prior to transplantation using a recently tested cryopreservation strategy (Table 3) (Lewis et al, unpublished), thus demonstrating that it should be possible to develop PDX tissue resources representing patients even from remote and underserved areas in the world where no active PDX development efforts may exist.

Finally, it is critical to recognize that the collections included in this review are exclusively from academic groups in Europe, Australia, and North America. Going forward, it will be important to include additional collections from other geographic regions that undoubtedly will have better representation of the patient demographics of the regions in which they function. Researchers and clinicians interested in participating in this International Breast 
Cancer Patient-derived Xenograft Consortium should contact the corresponding author (M.T. Lewis) to be added to the mailing list.

\section{Open Questions Regarding Generation and Use of Breast PDX Models}

Detailed protocols currently used for generation of patient-derived xenograft (PDX) models breast cancer have been published recently by De Rose et al and Zhang et al. [54,72], and will not be discussed in detail here. Similarly, the advantages and limitations of PDX models relative to clinical samples and established cell lines have also been discussed in detail elsewhere [76-79]. For the purposes of this review, we will briefly restate and highlight some of these strengths and limitations, but in the context of particular unresolved questions and issues currently being addressed by the breast PDX community.

\section{III.A. Are PDX really any better than xenografts made using long-established cell lines?}

A number of immortalized or transformed cell lines have been established and extensively characterized over the last several decades, notably the MCF series, the MDA series, and more recently the SUM series (see [80-82] and references therein). Extensive efforts have been made to correlate gene expression, genomic copy number changes, and mutations with growth characteristics and therapeutic responses [83-86]. Unfortunately, while all of these cell lines grow in vitro under tissue culture conditions, only a percentage of these will grow when transplanted as cell line xenografts, and a fewer will form metastases despite many of them being derived from pleural effusions and ascites [87-91]. Thus, a large proportion of the studies aimed at translational endpoints using cell lines have been conducted in vitro, rather than in vivo as cell line xenografts.

It is now appreciated that gene expression patterns under 2-dimensional in vitro culture conditions can be quite different than expression patterns observed under 3-dimensional culture conditions, or when cell lines are grown as xenografts in immunocompromised mice [92]. Similarly, drug sensitivity under varied conditions can be different for a given cell line [93]. Indeed, in transcriptome studies of clinical samples versus established cancer cell lines, cell lines clustered together regardless of the tissue of origin, rather than clustering with the clinical samples they were intended to model [94]. Given these differences, it is perhaps to be expected that cell line based studies have failed to translate clinically with high frequency, and thus may not be suitable to address many clinical questions [95,8]. In contrast, PDX lines are, by their nature, established and maintained in vivo, and have been shown to retain a remarkable degree of biological, histological, genomic, transcriptomic, and biomarker fidelity with their tumors of origin (see below).

Most established human breast cancer cell lines have been maintained in vitro over several decades, and in many different laboratories. Long-term culture has, in several cases, been associated with extensive clonal selection, and loss of heterogeneity [94,96]. Further, inconsistent handling, as well as both inadvertent and deliberate selection, are known to have led to genetic drift such that a multitude of sub-lines of individual parental lines now exist. As such, isolates of a given cell line (e.g. MCF7) can vary considerably from laboratory to laboratory with respect to genomics and gene expression [97,98]. Each sub-line can thus possess its own unique attributes (invasive vs. not, metastatic vs. not, adherent vs. not, drug 
resistant vs. sensitive, etc.). Further, since the tumor of origin from which a given cell line was derived cannot be studied in most cases, and only limited clinically-relevant data were collected, there is typically no way to evaluate what the original mutation spectrum in the patient was, or what the clinical behavior of the tumor of origin actually were. Taken together, these shortcomings limit the utility of established breast cancer cell lines for predictive/correlative studies. However, these shortcomings do not necessarily impinge on the use of established cell lines to investigate basic biological mechanisms. In contrast, PDX show behavioral, genomic, transcriptomic, and proteomic stability over at least 15 transplant generations in mice [54]. These attributes can be quality controlled from inception of the model, and in many cases, this can be done with direct comparison with the clinically annotated tumor of origin.

Finally, unlike the vast majority of long-established human breast cancer cell lines, a majority of PDX lines were established from primary tumors rather than tumor cells derived from pleural effusions, ascites, or other metastatic sites. Thus, in perhaps an important way, PDX lines may serve to complement existing cell lines rather than supplant them, depending on the question(s) being asked.

\section{III.B. To what degree do PDX models truly recapitulate the biology of the tumor of origin in the patient, particularly with respect to treatment response?}

One of the main open questions relates to whether PDX models retain the intra-tumoral heterogeneity of the tumor of origin. While many PDXs appear to retain the heterogeneity of the parental tumor of origin, loss of heterogeneity, or a "bottlenecking" clonal selection upon transplantation, has been observed in others [44]. An example of such selection came from comparative genomic sequence analysis of a primary tumor, a patient matched brain metastasis, and a PDX model derived from the primary tumor [37]. As expected, the metastatic lesion retained mutations found in the primary tumor, but also possessed de novo mutations and deletions not observed in the primary tumor. Also as expected, the PDX derived from the primary tumor retained the primary tumor mutations. Unexpectedly, the PDX showed the mutation spectrum found in the metastasis indicating that the metastatic subclone was present within the primary tumor, and that it was this aggressive subclone that grew as a PDX. Thus, it is critical to compare the tumor of origin with its related PDX line as carefully as possible, whenever possible, to ensure accurate recapitulation of as much patient/tumor biology as possible, including tumor heterogeneity.

As recounted above, the inability to relate a cell line to its patient of origin is one of the primary places where long-established cell lines fall short. Thus, cell lines simply cannot be used for this purpose. In contrast, PDX models, and the tumors from which they were derived, have been compared directly at multiple levels in several studies. At the histological level, several studies have demonstrated that PDX are virtually indistinguishable from the tumor of origin, including $\mathrm{H} \& \mathrm{E}$ stained sections, as well as by immunostaining for biomarkers such as ER, PR, HER2, and Ki67 positivity etc. At the genomic level, PDX show similar genomic rearrangements, copy number alterations, mutation profiles, and variant allele frequencies $[99,71-73,100]$, observed in the tumor of origin. These results 
demonstrate not only stability of the PDX when transplanted from one species to another, but also transplantability of clonal heterogeneity in many cases.

At the transcriptome level, PDXs generally show remarkable fidelity with respect to mRNA expression profiles (RNAseq) [101,73]. While proteomic comparisons between PDXs and their respective tumors of origin have not yet been completed, as stated previously, both transcriptomic and proteomic (RPPA) expression patterns have been shown to be remarkably stable across transplantation generations [54].

With respect to metastatic behavior, this is an open and active area of investigation across several groups. In general, PDX have been shown to produce circulating tumor cells, as well as disseminated micro and macro metastases to several distant sites $([71,102,54,103]$ and Miragaya et al, unpublished). When evaluated for fidelity with the metastatic behavior of the tumor of origin, PDX showed comparable metastatic site specificity ([71] and Miragaya et al, unpublished). As expected, PDX models are generally more metastatic in more immunocompromised hosts (e.g. larger metastatic nodules in NSG mice versus NOD/SCID; ALW unpublished data). This could be due to faster tumor growth and/or more permissive colonization of the distant sites. These observations warrant further investigation to test the generality of these initial findings, and to test the degree of influence of the immune system in the metastatic process.

\section{III.C. What is the status of Patient-PDX "credentialing" for relevance of PDX models in therapeutic studies?}

Among the most critical issues to be addressed is whether PDX models respond to a given treatment in a manner similar to the tumor of origin in the patient. If so, PDX models should serve not only as relevant as experimental models, but also as valuable translational research tools, especially if ultimately shown to have predictive value clinically. Again, this is a very active area of investigation in several groups. However, no "treatment standards" are yet available, largely due to the lack of comparative pharmacokinetic and pharmacodynamics data that would allow researchers to translate directly between PDX evaluation and clinical evaluation.

In preclinical treatment studies conducted to date, PDX showed comparable responses to the tumor in the patient of origin when treated with comparable therapeutic agents. An early study evaluating 7 xenografts showed an observed concordance of response between patient tumor and corresponding PDX of 71\% vs. a statistically expected concordance of $47 \%$ [68]. However, sample size was limited for direct comparison due to the types of treatments used clinically (adjuvant or post-radiation chemotherapy) in this patient cohort that could not easily be recapitulated in mice, thus statistical significance was not quite reached using this sample size (Kappa $=0.46, \mathrm{p}=0.08$ ). In a later study, a majority of xenograft lines tested also showed qualitatively identical treatment responses as the corresponding patient treated with a similar or identical agent in the neoadjuvant (before surgery) setting, and statistical significance was achieved using this increased sample size [54]. Overall concordance of responses was $\sim 92 \%(K=0.75, \mathrm{P}=0.003)$, and there was a significant association between the xenograft and patient-derived results (Fisher exact test, $\mathrm{P}=0.04$ ). While both studies were relatively small, taken together, PDX do recapitulate tumor responses seen clinically 
with good efficiency. Importantly, at least with respect to these selected Standard of Care agents, and under the specific conditions tested, this recapitulation does not appear to be influenced by the immunodeficiency of the host mice used. Thus, PDX models and associated data should serve as useful predictors of response in patients with at least some agents under some conditions. However, this hypothesis remains to be tested in a rigorous manner in both retrospective and prospective (co-)clinical trials.

\section{III.D. Which immunocompromised mouse model should be used for most efficient PDX generation while still retaining the highest possible fidelity with the human disease?}

A variety of immunocompromised, or immunodeficient, mouse models now exist that can be used as transplantation hosts to develop breast cancer PDX models (Table 3). While all mouse models listed are capable of generating PDX models under various transplant conditions, and using various sample types, a consensus has yet to be reached as to the "best" host to use. Thus, choice of immunocompromised host remains largely a question of investigator preference until rigorous head-to-head studies are conducted, and a large enough body of data is available for multivariate analysis. Such data need to be related not only to the various transplantation conditions being employed, but also to the characteristics of the underlying patient populations, and tumor types, being evaluated in order for meaningful conclusions to be drawn.

III.D.1. Athymic nude mice-Until approximately a decade ago, the most commonly used immunocompromised mouse model used for generation of breast cancer xenografts was the athymic "nude" mouse [104-106], which is homozygous for loss-of-function mutation of the Foxn1 gene (encoding the Forkhead box N1 transcription factor) (a.k.a. $n u$, Hfh11) [107,108]. The Foxn1 gene is essential for the development of the thymus and some ectodermal derivatives, including hair follicles (hence the "nude" phenotype), and leads to loss of functional T- and B-cells. The mice retain functional natural killer (NK) cells, macrophages, and antigen presenting cells (APC).

To support growth of estrogen-dependent breast cancer cell lines, athymic mice require supplementation with estradiol due to low endogenous levels of circulating estrogen [109112]. The same appears to be true for other immunocompromised mice - even if they may have higher estrogen levels, cell lines only grow when the mice are supplemented with exogenous estradiol. While historical rates of generating stable PDX lines have been relatively low using nude mice, alternative transplantation methods (e.g. subcutaneous transplantation of tumor fragments into the intra-scapular fat pad or flank), does appear to allow efficient PDX establishment (Table 3) ([68,113,114], Gomez-Miragaya et al, unpublished).

III.D.2. Rag1/Rag2 mice—Rag recombinase-deficient (Rag1 and/or Rag2) mice have been used sporadically for xenograft studies, mainly for generating cell line xenografts. However, these mice have not been used extensively for attempts to generate PDX lines (see Table 3). Like athymic nude mice, B- and T-cell function is abrogated [115] due to loss-offunction of the recombinases required for the somatic recombination of antibody chains and mature T-cell receptors. Rag knockout mice may be a useful alternative for some treatment 
response studies using anthracycline-based or other DNA damaging therapies because the consequences of Rag mutations are relatively specific to the hematopoietic system. As such, these mice can tolerate higher levels of DNA damage than mice carrying the SCID mutation (Prkdc, which encodes a ubiquitious DNA repair enzyme, see below) [116].

III.D.3. SCID mice-Most of the major breakthroughs made in efficient generation of PDX lines have been made using newer, more immunocompromised, mouse models. These include SCID (severe combined immunodeficiency disorder) mice which carry a mutation of the Prkdc gene (protein kinase, DNA activated, catalytic polypeptide) encoding a protein kinase required for somatic VDJ (variable, diversity, joining) region recombination of antibody chains and T-cell receptors, as well as for DNA repair. Such mice show B- and Tcell deficiency, but background-dependent leakiness does occur. SCID mice retain cellular immunity [117-121]. The SCID mutation is generally used in combination with other mutations that further cripple the immune system for xenograft work. However, SCID mice remain prone to premature death, due in part to their high prevalence of spontaneous T-cell lymphomas [121].

III.D.4. SCID/Beige mice-Combination of the Beige $(B g)$ mutation with the SCID mutation has been shown to enhance the take rate of human leukemias and other cell types, including breast cancers [122-125,54]. In addition to B- and T-cell deficiencies, disruption of $\mathrm{Bg}$ results in a lysosomal trafficking defect and eliminates NK cell function, but leads to a $\sim 3$-fold increase in the number of macrophages relative to the parental wild type Balb/C mice $[126,127,122,123]$. Macrophages are essential for normal mammary gland development. As such, this increase in macrophage content may be advantageous $[128,129]$. Further, recent data showing promotion of tumor invasion and metastasis by immature myeloid cells of the macrophage lineage may account for some of the advantages of this immunocompromised background [130]. Use of this genetic background allows stable take rates in excess of $20 \%$ under various conditions, but successful transplantation in this background is enhanced significantly by estradiol supplementation (Table 3) [54], likely by an ER-alpha-mediated stimulation of bone marrow-derived monocytes [54,131].

III.D.5. NOD/SCID mice-A major advance for the generation of PDX models came after genetic introgression of the NOD (non-obese diabetic) mutation in to the SCID background, which compromises cellular immunity, via impaired function of NK, APC and macrophage cells. While impaired, presence of NK and macrophages in athymic and NOD/SCID mice can lead to elimination of tumor cells over time [132-134]. Use of this background has allowed take rates in excess of $20 \%$ on a routine basis (Table 3) (see $[71,135,69,136]$ and Gomez-Miragaya et al., unpublished; Piwnica-Worms et al., unpublished).

III.D.6. NOG and NSG Mice-Development of the NOD/SCID background has continued with the addition of IL2-receptor gamma truncation/disruption mutations ("NOG" or "NSG" mice, respectively) which compromises the mouse immune system further by impairing cytokine signaling involved in innate cellular immunity [65,137,138]. Use of this background has been extensive across multiple groups, and has allowed take rates in excess of $20 \%$ overall to be achieved on a routine basis (Table 3) 
$([69,71,54,37,139,74,140,73,141]\}$ and Gonzales-Suarez et al., unpublished; Bult et al. unpublished). The primary distinction of the NSG and NOG strains is that the function $I / 2 \mathrm{rg}$ in NSG is completely ablated. In NOG, the II2rg mutation still produces a protein product that can bind to cytokines, but there is no signaling activation. NSG mice are less susceptible to thymic lymphomas than NOD/SCID mice, and have a longer lifespan, making them wellsuited for engrafting slower growing human tumors.

An interesting modification of the NSG is the NRG strain, which replaces the SCID mutation with a Rag1 mutation. These mice were used recently for the intraductal injection approach for PDX development [141]. Evaluation of NRG mice in experimental therapeutic studies involving DNA-damaging agents would be of considerable interest.

The NSG recipient mouse has been shown to support greater engraftment of human hematopoietic stem cells (hu-CD34+ cells) than some other currently available strains $[137,142]$. As a consequence NSG mice can be engrafted with functional human immune systems permitting the potential to study primary human tumors in vivo in the presence of a human immune system. However, NSG mice are also reported to develop lymphocytic neoplasms occasionally from human B- and T-cells co-transplanted with the human tumor fragments, which rapidly outgrow human epithelial tumor cells $[143,144]$. Nonetheless, NSG mice are currently the most popular choice for developing breast cancer PDX, with the majority of the consortium groups using NSG exclusively or in combination with other strains.

\section{III.D.7. Comparisons of immunocompromised hosts with regard to breast cancer PDX modeling-With multiple host mouse models capable of generating PDX} lines under a variety of conditions, using a broad range of tumor types, it is important to note that controlled head-to-head comparisons of single tumor fragments transplanted into multiple immunocompromised host models under otherwise identical transplant conditions have not been conducted extensively. Thus, it is not currently possible to state definitively that one immunocompromised mouse model is superior to any other for generating breast PDXs. Similarly, comparison of take rates achieved between various groups is difficult due to considerable differences in tumor types used for transplantation (e.g. low grade vs high grade primary cancers, primary tumors vs. metastatic tumors, before or after treatment) and patient cohort characteristics (e.g. ethnically diverse or not).

Limited side-by-side comparisons of engraftment efficiency have been performed suggesting the SCID/Bg or NOG/NSG backgrounds may provide superior engraftment of various types of human cells [122-125]. Indeed, when comparing two similar cohorts of breast cancer patients, primary tumors showed equivalent take rates in either the SCID/Bg or NSG backgrounds [54]. However, this study was not a head-to-head comparison using exactly the same patient sample into both backgrounds simultaneously. While the range of PDX models produced in these two backgrounds was similar, it remains possible that each genetic background might favor the establishment of different types.

Some studies have now shown that positive engraftment of breast tumors into certain mouse strains correlates with high tumor grade or poor patient outcome $[145,71,66,99]$ Whether the 
prognostic value of engraftment would extend to more immunocompromised hosts, or whether retention of some cellular immunity in the host provides more information regarding tumor aggressiveness in the patient is still unknown.

\section{III.E. What is the best transplantation site?}

A variety of transplantation sites are available in the mouse, and several have been used in attempts to generate breast cancer PDX models. Tissue can be transplanted into the anterior compartment of the eye [146,147], under the renal capsule [148-151], within the intrascapular fat pad [68], subcutaneously (ear, flank, etc.), orthotopically within the mammary fat pad (either the intact (IFP), or epithelium —-free "cleared" (CFP) fat pad) [152] or injected into the mammary ducts themselves $[153,154,141]$.

In addition to these approaches for modeling primary tumors"experimental metastasis" methods have been developed in which tumor cells are injected through the tail vein, the iliac artery, or by intracardiac injection, allowing establishment of tumors at other organ sites including bone, brain, lung, and liver (e.g. [155-160] and references therein). A bone-tobone xenograft experimental metastasis model has also been developed [161].

With respect to PDX model development, subcutaneous and orthotopic transplantation sites are generally used (Table 3), with orthotopic transplantation into the mammary fat pad considered preferable by some as it should more closely represent the human breast with respect to the microenvironment. However, the intraductal approach is also attractive with respect to the range of orthotopic options available. For example, in one study, cells from 16 tumours that successfully formed primary grafts after intraductal injection failed to engraft at 26 subcutaneous injection sites [141], but direct comparison of intraductal with sophisticated extraductal grafting techniques has not been performed.

\section{III.F. Is it necessary to eliminate endogenous mouse epithelium from the mammary fat pad (i.e. "clear" the fat pad) for efficient orthotopic transplantation?}

Elegant transplantation studies conducted nearly six decades ago [162,152,163] demonstrated that the adult mammary gland contains growth-quiescent epithelial regenerative stem cells that are distributed throughout the entire gland. These stem cells could be activated to self-renew upon transplantation of small duct fragments ( 1000-2000 cells) into the epithelium-free mammary fat pad of recipient mice, and were capable of regenerating a morphologically normal and functional, ductal tree. However, these same fragments would not regenerate a ductal tree in the presence of pre-existing ducts in the recipient animal. Thus, the presence of endogenous normal epithelium is inhibitory to transplanted epithelium, thereby necessitating removal of the endogenous epithelium ("clearing") for the transplant to grow.

In contrast, neoplastic tissue transplanted into an intact fat pad will grow in the presence of endogenous normal epithelium. However, this ability does not necessarily mean that inhibitory signals do not exist, only that neoplastic tissue is capable of overcoming them, or is unresponsive to them, should they exist. Thus, while neoplastic tissue may be able to overgrow normal epithelium, removal of whatever inhibitory influences may exist might allow neoplastic tissue to grow even better. Conversely, it is formally possible that normal 
epithelium could promote growth of neoplastic tissue. These alternative hypotheses have not been tested in a controlled manner.

From inspection of Table 3, use of the intact mammary fat pad (IFP) does not appear to interfere with effective transplantation of primary tumor tissue. In fact, there are preliminary indications that the IFP may be superior to the CFP for transplantation of both fresh, and previously cryopreserved, tumor tissue (Table 3 ). That said, the continued presence of endogenous mouse epithelium may complicate some downstream molecular analyses (e.g. transcriptome arrays, Reverse Phase Protein Arrays (RPPA) etc.), and so use of the IFP may not be desirable in all instances.

\section{III.G. Is estradiol supplementation necessary? If so, what is the most effective way to deliver it?}

With the possible exception of metastatic ER+ breast cancer, it has proven difficult to establish PDX models of primary, particularly lower grade, ER+ luminal A tumors. Further, once established ER expression can be lost over the course of passaging from mouse to mouse (e.g. [68,57,164], Miragaya et al. unpublished), though many current studies have not shown this behavior. These difficulties are offset, in part, by the fact that ER+ cancers account for approximately $75 \%$ of all breast cancers, thus offering more opportunities to make successful PDX models.

In attempts to increase the take rate of ER+ tumors, various forms of estradiol supplementation have been used, ranging from commercially prepared slow-release plastic pellets (e.g. Innovative Research), to hormone-loaded silastic tubes, or bee's wax pellets. To date, progesterone supplementation, either alone or in combination with estradiol, has not been evaluated. Unfortunately, in addition to significant urinary tract complications associated with the use of estradiol-containing implants of all sorts, the major issue with this approach is that the implant becomes depleted of hormone over time, requiring periodic replacement if hormone levels are to be maintained long-term. To address these issues, several groups have revisited use of an old method by testing the ability of estradiolsupplemented drinking water for its ability to support PDX growth with promising results (Table 3) (see $[68,165-168,136]$ Lewis et al., unpublished). Given the significant limitations of delivery using implants, estradiol-supplemented drinking water may be a superior method of delivery. However, it remains unclear whether rates of PDX establishment will be comparable to those using other delivery methods.

While most groups engaged in PDX generation use some form of estradiol supplementation for ER+ tumors, use of supplementation is not always used when transplanting ER- tumors (Table 3) $[71,114,113]$ - the reasoning for not using supplementation being that ER- tumors should not require estradiol supplementation for their growth. However, comparison of stable take rates of primary cancers from statistically similar cohorts in the SCID/Bg host strain, with and without supplementation with slow-release estradiol pellets, demonstrated that supplementation increased the stable take rate almost 10 -fold, from $2.6 \%$ without supplementation (only a single TNBC PDX generated from 38 patients attempted) to $21 \%$ with supplementation (15 PDX representing multiple IHC subtypes from 70 patients attempted) in this host background [54]. These data indicating a requirement for estradiol 
supplementation were consistent with previous studies showing that estradiol supplementation stimulates growth of breast cancer xenografts, including ER-negative xenografts $[71,169,170,69]$. Subsequently, the stimulatory effect of estradiol supplementation on ER-negative tumor was investigated specifically and shown to be due, in part, to an effect on bone marrow-derived myeloid cells that promote angiogenesis and tumor growth that was dependent on ERa [131,171].

Of potential significance, several groups have successfully used NSG mice without estradiol supplementation (Table 3), suggesting that unlike SCID/Bg, successful transplantation in NSG animals may not require supplementation. However, there may be significant differences in the patient cohorts and tumor characteristics from one group to another that may contribute to this apparent difference. That said, the intraductal approach appears to also one to grow ER+ cell lines and PDX in the absence of endogenous hormones [154,141].

It will be critical to address these potential host background differences going forward.

\section{III.H. How can lower grade tumors, ductal carcinoma in situ (DCIS), and normal tissue be grown with higher efficiency?}

While it has been comparatively easy to establish PDX models from metastatic sources such as ascites and pleural fluid, as well as from high grade, more aggressive primary tumors from the breast itself (Table 3), it has proven relatively difficult to establish PDX from grade I/II tumors, DCIS, and normal breast epithelium [153,75,54,66,70,114,113].

One possible explanation for elevated take rates in high grade primary tumors could be a higher frequency of tumor-initiating cells (TIC) (a.k.a. cancer stem cells) relative to lower grade tumors [172,173]. In one study, the frequency of cells expressing ALDH1 (aldehyde dehydrogenase 1), a marker associated with TIC properties in some, but not all, breast cancers, predicted the rate of engraftment as a PDX. The general hypothesis is that the higher the proportion of TIC, the higher the likelihood of successful transplant. This hypothesis makes intuitive sense from a statistical standpoint. However if this were the entire explanation for differential take rates, transplantation of larger fragments of lower grade tumors should address the problem of low take rates because more TIC would be present in the transplant. Given the widespread failure of several investigators to establish lower grade tumors under a variety of conditions, this explanation, while plausible, is not likely to account entirely for the elevated take rate in high grade cancers.

One other plausible explanation for differential take rates of low grade (including DCIS) versus high grade cancers is that immunocompromised mouse hosts do not express one or more factors that low grade tumors require for growth in mice - factors that at least some higher grade tumors do not require (analogous to a shift from hormone-dependent to hormone-independent tumor growth in some ER+ breast cancers).

In addition to this potential contribution of tumor evolution/progression, there are several known incompatibilities between human and mouse ligand/receptor pairs that may interfere with the ability to transplant human tumors into mice efficiently. For example, several mouse ligands (e.g. prolactin, hepatocyte growth factor (HGF), interleukin-6 (IL-6)) do not activate 
their human receptor counterparts [174-176]. Thus, tissue-appropriate expression of one or more of these human ligands either as transgenes, or as knock-in constructs, in an immunocompromised mouse background may be necessary to stimulate growth of lower grade tumors.

One technical modification that may help with growth of lower grade tumors is the use of Matrigel or similar basement membrane extract preparation in the transplantation process. Head-to-head comparisons of take rates with and without Matrigel using otherwise identical host mice and tissue sources have not been conducted. That said, a comparatively high take rate of $37 \%$ (10 of 27 patients) was achieved [69] using primary tumor fragments or metastatic cells (pleural fluid/ascites) coated in Matrigel and implanted into the intact fat pad of either estradiol supplemented NOD/SCID or NSG mice. However, this reported take rate appears to have been attenuated with additional patient samples attempted (Table 3). There also may be some indication that the use of Matrigel in the context of the IFP may help somewhat (Table 3). However, using previously cryopreserved tissue, the addition of Matrigel under otherwise identical transplant conditions does not appear to enhance the take rate (Table 3).

Another promising approach is the use of intraductal injection of cells. This method has been used to grow DCIS [153], ER+ and HER2+ breast cancer [154] and molecular apocrine cancers [141], with excellent recapitulation of the biology of the source tissue. The intraductal approach may allow human epithelium to interact with normal epithelium in much the same way that it would in a patient, thereby perhaps allowing growth whereas isolated fragments of human tissue may not grow in the absence of such interactions.

\section{III.H.1. Progress toward development of mouse models of human breast} premalignant lesions-For a comprehensive review of human DCIS models including in vitro models, please refer to Kaur, $\mathrm{H}$ et al. [177].

Efforts toward developing models of premalignant breast lesions go back to 1975 when Outzen and Custer reported transplantation of small fragments of human "cystic hyperplasias" into cleared mammary fat pads of nude mice and the lesions were maintained for 2-3 months [178]. The hyperplastic lesions proliferated in mice and recapitulated the histologic patterns of the original patient biopsy specimens [60]. Other investigators also reported that fragments from human breast atypical hyperplasias could be maintained for up to $\sim 6$ months in nude mice and sometimes, the lesions would dedifferentiate meaning that they potentially progressed by forming disorganized epithelial hyerplasias. Three transplantation sites were used, cleared mammary fat pad, subcutaneous and intraperitoneal. The cleared mammary fat pad site was reported to result in the highest take rate (reviewed in [178]). Later a study in 1997 reported transplantation of fragments from 25 cases of human ductal carcinoma in situ (DCIS) in the back of athymic nude mice [179]. Fragments were recovered 2-8 weeks after transplantation and maintained their DCIS components in $93 \%$ of transplants [179]. The purpose of this study was to analyze ER expression in the transplanted DCIS and to assess their response to estrogen supplementation. However, the authors reported no expansion in response to hormonal supplementation during the 8 week follow up. In a more recent study, human DCIS tissue fragments were implanted 
subcutaneously in athymic nude mice in order to study the therapeutic efficacy of a farnesyl transferase inhibitor. The DCIS xenografts were maintained for up to 21 days and showed a take rate of about 66\% [180]. Recently, Espina V, et al., demonstrated successful xenotransplantation of freshly procured DCIS organoids and in vitro propagated spheroids derived from patient DCIS biopsy or surgical specimens. This group reported that tumors formed in mice at a rate of $\sim 80 \%$ (21/27 cases transplanted) from both freshly procured organoids from DCIS of any grade or propagated DCIS organoids passaged in vitro for 2-12 months.

Towards the development of cell lines that would mimic the histologic and molecular features of premalignant breast lesions in xenografts, Miller, FR and colleagues developed MCF10AT cell line models. Xenografted lesions derived from MCF10AT cells generated the full spectrum of human breast lesions including normal ducts, hyperplasia, atypical hyperplasia, carcinoma in situ and invasive cancers [181,182]. A clonal derivative of a tumorigenic variant of MCF10AT xenografts, MCF10DCIS.com, produced comedo DCIS when transplanted at early passages into cleared fat pads of immunodeficient mice. Subcutaneous injection of MCF10DCIS.com into nude mice resulted in rapidly growing lesions that were predominantly comedo (a more-aggressive type of DCIS with central necrosis) [178]. When transplanted subcutaneously, the MCF10DCIS.com lesions appeared in about 3 weeks and were composed of luminal epithelial cells surrounded by both a myoepithelial cell layer and a basement membrane. Some areas of early lesions progressed to invasive cancers in about 5 to 6 weeks [183]. Another premalignant cell line model SUM225CWN was derived from a chest wall recurrence of a ductal carcinoma lesion [184]. Similar to those of MCF10DCIS.com, xenografts of the SUM225CWN cell line form DCISlike lesions in NOD-SCID mice in as early as 2 weeks [185].

With the idea that human DCIS initiates inside the ducts, Behbod, F et al., utilized the intraductal transplantation technique [153]. This approach, referred to as mouse-intraductal (MIND) involves injection of epithelial cells derived from DCIS patient samples or cell lines directly into the immunocompromised mouse mammary ducts. This is the first model to capture the natural evolution of human DCIS in mice since, similar to humans, the cancer cells initially form in situ lesions inside the mammary ducts followed by invasion as they bypass the natural barriers of ductal myoepithelial cell layer and basement membrane. Initially, MCF10DCIS.com and SUM225CWN cells as well as one case of primary human DCIS were utilized. The DCIS-like lesions generated from the MCF10DCIS.com (DCIS.com) and SUM225CWN cell lines formed DCIS-like lesions as early as two weeks and slowly progressed to invasive lesions in 10-14 weeks [153]. Later, in 2011, this group reported reproducible growth and expansion of epithelial cells derived from patient DCIS biopsy and/or surgical samples as well as hyperplasias in NOD-SCID IL2rg mice by the MIND method. The xenografted DCIS like lesions and hyperplasias expressed similar biomarkers (ER, PR and Her-2) as the original patient samples. The DCIS like lesions generated by the primary DCIS cells in MIND models formed in situ lesions as early as 8 weeks and a fraction of those slowly progressed to invasive lesions in 6-12 months following transplantation (Behbod, F unpublished results). The take rate for primary DCIS MIND models is $\sim 50 \%$. A key difference of the MIND method is that pure epithelial cells 
are injected intraductally as opposed to previous methods that transplanted organoids or pieces of tissues in the cleared mammary fat pads of immunocompromised mice.

\section{III.I. Can "Humanization" of Immunocompromised Mice Enhance Take Rate and Improve Translational Relevance?}

There are currently two different classes of "humanization" methods that are being explored for their ability to enhance PDX growth, and perhaps provide a more biologically similar environment as in the tumor of origin.

III.I.1 "Humanization" of the mammary fat pad-A few groups have attempted to increase the efficiency of primary tissue transplantation by "humanizing" the mammary fat pad of mice with the introduction of an immortalized human fibroblast cell line into the mammary fat pad prior to xenograft transplantation $[75,87,186]$. Use of this methodology allowed organotypic growth of normal human mammary epithelium, and appears to allow PDX establishment under some circumstances (Table 3). However, Zhang et al [54] showed that provision of immortalized fibroblasts attenuated take rates considerably using statistically comparable cohorts in the SCID/Bg background reducing the rate from $21.4 \%$ to $3.4 \%$ under otherwise identical transplantation conditions. Thus, it remains unclear whether immortalized fibroblasts enhance PDX take rates.

Aside from immortalized fibroblasts, it is also possible that co-transplantation of mesenchymal stem cells may enhance PDX take rates. These cells were shown to enhance mammosphere formation in vitro [187,188], and to stimulate growth and metastasis of established xenografts in vivo $[71,189,190,175]$. However, this approach has not yet been tested extensively.

\section{III.I.2. "Humanization" by reconstitution of the human immune system in immunocompromised mice-A disadvantage of any xenograft as a model for human} cancer is growth of the tumors in immunocompromised mice, which is required in order to avoid rejection of the tumor by the host mouse immune system. Lack of normal immunity in tumor xenografts is an important caveat, given the well-established, multiple roles of the immune system in tumor initiation and growth, metastasis, and response to therapy. In most patients, tumors arise in the presence of a functional immune system, and the tumor evolves to evade immune rejection under selective pressure [191]. Once a tumor is detectable it has already avoided immune-mediated rejection, and thereafter, the immune system actually plays a paradoxical role in promoting tumor progression and metastasis [192-194]. For example, macrophages can assist with tumor cell intravasation to facilitate tumor dissemination [195]. Myeloid-derived suppressor cells can promote angiogenesis and suppress adaptive immune responses [196], and regulatory T cells reinforce the immunosuppressive tumor microenvironment [197].

On the other hand, it has been clear for a number of years that the immune system can, in some cases, be successfully stimulated to eradicate tumors. Indeed, recent advances in immunotherapy using immune checkpoint inhibitors have led to exciting therapeutic results in certain cancers $[198,199]$. The immune system is also instrumental in sustaining tumor regression upon oncogene inactivation [200], which is highly relevant when considering 
therapeutic effects. Therefore, incorporation of a functional or partially functional human immune system into xenograft models might more accurately model human breast cancer growth, metastasis, and response to therapy, particularly those known to involve an immune system function in their mechanism of action.

Generation of mice with reconstituted human immune systems was first accomplished in 1988 [201], and is now commonly used to study human blood cell development and diseases of the hematopoietic system [65]. The idea of using mice with 'humanized' immune systems to study human cancer is not new, but until recently has been mostly focused on tumors of the hematopoietic lineage. Immune humanization in mice carrying human breast cancers is now feasible [202], with two key stipulations: (1) the mouse host has to be appropriate for growth and development of human tumor cells and human immune cells; and (2) the immune system must not recognize the tumor as foreign and reject it (graft vs. tumor reaction). State-of-the-art strategies, as well as caveats, have been recently reviewed elsewhere [203-206].

In summary, it has become clear that the "tumor cell-centric" approach to breast cancer therapy may not be sufficient to eradicate the disease, and a dual approach targeting both the tumor and its specialized microenvironment might be more effective [207]. Many promising therapies for breast cancer rely on an effective anti-tumor immune response, and they need to be tested pre-clinically in animal models before entering trials. Examples include vaccines for breast cancer prevention or inhibiting outgrowth of occult metastasis [208]; drugs to prevent macrophage recruitment into tumors where they promote metastasis [209]; or new immune checkpoint inhibitor combinations [210]. In all cases, a better understanding of human tumor-immune interactions is needed. Future development of PDX models in mice with matched, functioning human immune systems may hold potential to advance breast cancer research and lead to new treatments.

\section{III.J. What do we need to do to make PDX repositories truly clinically relevant? Toward development of data standards for "clinical" annotation of patient breast cancer samples and their associated PDX models}

As a newly formed international consortium, we herein report details of a large collection of breast cancer PDX models that recapitulate patient biology to a high degree. However, the patient-related clinical data, and PDX-related data collected by each individual group varies significantly, both in terms of content and terminology used. This review therefore provides an opportunity to begin a discussion about development of an international data standard that can be adopted by all PDX generating groups to allow direct comparison of collections worldwide, and provide the foundation for larger-scale international, multi-institutional collaborations. Ideally, data elements used should integrate well with existing data repositories and portals such as GEO, Oncomine, and cBioPortal etc. by having a shared conceptual understanding and similar terminology that allows direct mapping of data elements between PDX resources and data portals. Significant progress has been made in this area, including community discussions about standards for data format and content that will enhance data sharing and integration, which will be discussed in detail at a later date. 
There are two broad classes of data that can be collected: clinical data about the patient and tumor of origin, and PDX-centric data about the characteristics of the xenografts themselves. Within these two broad classes, the amount of data that can potentially be collected is relatively large, while the ability to collect detailed data may be limited by personnel availability and financial support. In particular, with patient privacy laws in effect in various countries, care must be taken to firewall personally identifiable health information from other data that can be shared publicly without concern that privacy will be compromised. To accomplish this division requires dedicated "clinical" personnel with clearance to access and abstract clinical data, and an independent group of dedicated "PDX" personnel with access to the abstracted clinical data, as well as PDX-based data elements and datasets. Finally, both of these efforts require significant involvement of bioinformatics and software development expertise for proper integration.

Clinical data can be collected with varying degrees of ease, and can be divided into what might be considered a "minimal", or "essential" data set, and a more expanded "ideal" data set at both the patient level and the sample level. At the patient level, it is essential that one knows the gender of the donor, the clinical event point that defines the sample type(s) that have been collected from the patient for use in PDX generation (e.g. Benign/Normal, Primary tumor, Second Primary Tumor, Local Regional Recurrence, Distant Metastasis, Unknown) and pathological stage (including nodal status etc).

In addition to these minimal data, there are several other data elements that greatly increase the utility of a renewable tissue resource for use in translational studies and drug evaluation. These include, patient age at each clinical event point (e.g. biopsy, surgery at which time the sample used for generating a PDX was taken), parity history, race, ethnicity, family history of cancers, vital status and date of recording, and any sites of distant metastasis. These data would ideally also include treatments received by the patient, the timing of treatment relative to the time of tissue collection for the production of PDX models, and the treatment response of the tumor of origin (most easily evaluated in the neoadjuvant setting).

At the sample level, minimal data include pathological diagnosis of the sample taken, hormone receptor status (ER/PR) and percentage of positivity, HER2 status, and germline BRCA1/2 mutation status of the tumor of origin for the resulting PDX lines to be maximally useful. Additional data of interest related to the sample used for PDX generation include Ki67 labeling index, status of commonly mutated genes like TP53 and PIK3CA, pathologic stage and grade, molecular subtype (by multiple means), and treatment status at the time of collection. Short tandem repeat (STR) analysis is also essential, whenever possible, to ensure accurate patient/PDX relationships. Given the recent reports of selective outgrowth of Epstein-Barr virus-positive human lymphomas in attempts to generate solid tumor PDX models $[143,144]$, it is imperative that each PDX model be validated appropriately with cytokeratin and CD45 immunohistochemical staining.

Because the PDX itself is a renewable sample type, tissue is not limiting. Thus, the PDX can be characterized to a high degree without concern of exhausting the tissue, although maintaining low passage lines is a clear priority. Key PDX-based data types are essentially identical with sample-level data types collected clinically. Namely, it is critical to confirm 
ER/PR/HER2 status in the PDX at different passages, and to conduct STR analysis to establish the unique identity of the PDX line and to establish the direct patient/PDX relationship whenever possible, and for downstream quality control measures to ensure PDX identity and integrity over what are likely to be decades of passage in the future.

In addition to these minimal data, other data that are useful are PDX growth rates (doubling time), metastatic frequency (CTC, lung, liver, bone, lymph node, brain etc.), and any number of "-omics" characterizations. The "-omics" characterizations possible to generate include, but are not limited to, genomic copy number alterations, mutation status in various genes (whole genome sequencing, exome sequencing, Sequenom, SNP analysis etc.), methylome, gene expression at both the RNA level (RNAseq, Array-based, QPCR etc.) and protein levels (Reverse phase protein array, mass spectrometry, Western blot, CyTOF), metabolome (mass spectrometry-based), among other possibilities. All data can then be correlated to any subsequent behavior or response that a given PDX, or set of PDX models, may have to experimental manipulation. Such correlations should be particularly important for evaluation of drug treatment responses (any number of agents, but specifically standard of care agents). To be particularly powerful, PDX-based -omics characterizations should be matched to the corresponding data derived from the tumor of origin whenever possible. However, given that patient samples are typically limited by size, this is not always possible.

\section{Summary of Strengths and Limitations of PDX Models For Translational Research and Drug Development}

PDX models are potentially important tools for identifying mechanisms of de novo and acquired drug resistance, for identifying new biomarkers of breast cancer biology, for driving drug discovery, and for evaluation of new experimental therapeutics. Although superior to cell lines in recapitulating tumor heterogeneity, PDX models are also biased towards more aggressive tumors and the rate of engraftment can be an independent predictor of patient outcome. While the majority of PDX models represent TNBC, there has been substantial improvement in establishing HER2+ and ER+ luminal B tumors. As predicted, more differentiated ER+ tumors with a low Ki67 staining index are very difficult to engraft, and in cases where they do engraft, it is likely that selection for the most undifferentiated components of the tumor has occurred, resulting in a tumor quite different from that in the original patient. Thus, rates of engraftment are skewed towards the most undifferentiated subtypes of breast cancer and do not fully encompass inter-tumor heterogeneity.

The recent findings that the clonal dynamics of tumors are highly variable, ranging from minor changes on engraftment to extensive changes that accompany selection for a minor clone of originating cells, adds a further degree of complexity [44]. Nevertheless, polyclonality is generally well-represented by breast xenografts, and they continue to serve as useful models provided their clonal repertoire is taken into consideration. Although metastatic lesions demonstrate improved take rates and growth, they cannot be used to study the process of metastasis from naïve tumors.

One of the major limitations of the PDX model is the deficiency of the mouse host immune system and selectively inappropriate microenvironmental influences. Severely 
immunodeficient hosts must necessarily be utilized but these inevitably alter the growth kinetics of many PDX tumors and preclude evaluation of immune-modulatory therapies. The NSG mice is currently the most widely used strain, but these lack natural killer cells, B and T lymphoid cells. Humanization of the immune system could in theory be achieved by mobilizing peripheral blood stem cells from the same patient, although this remains challenging on more than one front. Other options include humanization of the mouse immune system by co-engraftment of human bone marrow cells [211].

In addition to immune system deficiency, PDX models lack human stromal components such as the different fibroblast populations, endothelial cells and adipocytes, being replaced by their mouse counterparts which do not function identically. The growth factors and stromal requirements necessary for effective engraftment are poorly understood and human fibroblasts are rapidly out-competed by mouse stromal cells following transplantation [71]. Genetic targeting of multiple human cytokine genes into their respective loci within mice [212] might improve tumor engraftment through the provision of crucial stroma-derived species-specific cytokines. In addition, one might expect that co-engraftment of mesenchymal stem cells or cancer-associated fibroblasts could enhance tumor growth and stabilize tumor heterogeniety. Despite these ideas, the key to fully efficient tumor engraftment is not still known.

PDX models have been shown to recapitulate the drug sensitivity responses observed in the tumors of patients, from which they were derived. However, the implementation of PDX mice as 'Avatar models' to guide clinical decisions will require significant advances in this area, including rigorous comparison of pharmacokinetic and pharmacodynamics for various agents that will allow "preclinical trials" in PDX-bearing mice to be as comparable as possible to clinical trials as conducted with patients. Aside from the limitations owing to lack of a human immune or stromal system, one of the limiting issues is the time-scale required to establish PDX models for drug testing. We also need to collect data about adverse drug reactions in different mouse strains. Furthermore, not all patient tumors engraft, adding a level of unpredictability. In order for PDXs to be relevant to the individual patient, the engraftment rate and time required for engraftment need to be dramatically optimized and standardized, without compromising the biological properties of the original patient tumor.

At this stage in their credentialing, PDX models best serve as basic and translational research tools, where they can have considerable impact. One of the best examples has been seen in the case of colorectal cancer, where PDX studies showed that tumors with a mutated $K R A S$ gene were not responsive to cetuximab [213], closely mimicking that seen in large clinical trials. These results provide compelling support for PDX models as predictors of clinical response and their further implementation could circumvent long-term, costly clinical trials in the future [214].

\section{Focus for the future}

At some point, perhaps even very soon, the more aggressive forms of breast cancer will be represented well enough in the PDX community that it is no longer necessary to expend 
additional resources and effort to develop new PDX lines to represent them. Rather, it may be more fruitful to redirect resources to generate PDX lines for underrepresented tumor types or patient populations. These underrepresented tumor types and populations may offer insights into breast disease that would not be found otherwise, and would likely facilitate development of personalized medicine strategies.

It has already been mentioned that ER+ Luminal A and HER2+ tumors, grade I/II tumors, DCIS, and hyperplasias are significantly underrepresented in the PDX collections reported herein, but the increased use of the intraductal approach may remedy this situation. Similarly, there are very few claudin-low or metaplastic tumors present in the current collection; these are tumors with very poor prognosis and limited treatment options. As such, focused effort to establish PDX models representing these underrepresented tumor types may be preferable to the broader efforts currently underway.

In addition to these more familiar tumor types, there are other classes of tumors that are also underrepresented, on which focused attention might be warranted. For example, while some models do exist, tumors from Hispanic, African American, Asian, and Native American, and other indigenous peoples, are still underrepresented. Similarly, while males do develop breast cancers, there are presently no male breast cancers represented in the PDX collections presented herein. Finally, if the proper infrastructure were developed, we have the opportunity to try to generate PDX models from areas of the world in which health care is limited, and PDX generation efforts are entirely lacking. Together, these rare and underrepresented PDX models may provide unexpected insights that cannot be foreseen.

\section{Conclusions}

1. PDX models representing clinically-relevant subtypes of breast cancer are available as phenotypically stable, renewable tissue lines.

2. Breast cancer PDX recapitulate many key aspects of the biology of the tumor of origin and therefore may serve as excellent models for translational research.

\section{Supplementary Material}

Refer to Web version on PubMed Central for supplementary material.

\section{Acknowledgments}

Samuel Aparicio - Supported by the BC Cancer Foundation, Canadian Breast Cancer Foundation, CIHR, Canadian Foundation for Innovation, Stand Up to Cancer Canada, Canadian Cancer Research Institute, Terry Fox Research Institute.

Fariba Behbod - Supported by R01-NIH/NCI-R01CA172764, NIH/NCI-R21CA187890, AACR-Breast Cancer Research Foundation-2014 Translational Breast Cancer Research and NIH/NCI- R21CA185460.

Cathrin Brisken -The research leading to these results has received support from the Swiss Cancer Ligue, the SNF and Innovative Medicines Initiative Joint Undertaking (grant agreement $n^{\circ} 115188$ ) for the PREDECT consortium (www.predect.eu) resources composed of financial contribution from EU-FP7 and EFPIA companies in kind contribution. The Web address of the Innovative Medicines Initiative is http://www.imi.europa.eu/.

Carol J. Bult - This work was supported in part by the Maine Cancer Foundation, The Jackson Laboratory Director's Innovation Fund, and JAX Cancer Center grant P30 CA034196. 
Matthew Ellis - Dr Ellis is a McNair Medical Institute Scholar and a CPRIT Established Investigator (CPRIT RR140033)

Robert Clarke \& Denis Alferez - This work was funded by Cancer Research UK and Breast Cancer Now. We would like to thank all patients who donated tissue to this study, and the Manchester Cancer Research Centre Biobank for consenting patients and collecting tissue

Eva Gonzalez-Suarez. This work was supported in part by grants to Eva González Suárez by the Spanish Ministry of Economy and Competitivity MINECO and from the ISCIII (SAF2008- 01975, SAF2011-22893, SAF2014-55997), PIE13/00022, co-funded by FEDER funds/ European Regional Development Fund, and JAX Cancer Center grant P30 CA034196. (ERDF)- a way to build Europe-), by a Career Catalyst Grant from the Susan Komen Foundation and by institutional funds provided by the Generalitat de Catalunya

Richard Iggo - This work was supported by the "Fondation pour la lutte contre le cancer et pour des recherches medico-biologiques", the INCa-DGOS-INSERM 6046 SIRIC BRIO grant, and the French Cancer League (Comité de la Charente Maritime).

Peter Kabos - NIH grant CA164048, Grohne Cancer Research Fund.

Michael T. Lewis - This work was supported in part by the Breast Cancer Research Foundation, the Emma Jacobs Clinical Breast Cancer Fund, the Susan G. Komen Foundation, Cancer Fighters of Houston, BCM Cancer Center grant P30 CA125123, BCM Breast Cancer SPORE P50 CA50183, NIH/NCI grant R01 CA112305, NIH/NCI grant U54 CA149196. The authors also acknowledge the joint participation by Diana Henry Helis Medical Research Foundation through its direct engagement in the continuous active conduct of medical research in conjunction with Baylor College of Medicine and its "Blood-borne BioMarkers for Detection of Breast Cancer" Program.

Shunqiang Li - Susan G. Komen for the Cure (BCTR0707808, KG090422, and PG12220321), Breast Cancer Research Foundation, CTSA grant UL1 RR024992, The Fashion Footwear Charitable Foundation, Inc.

Geoffrey J. Lindeman and Jane E. Visvader - receive funding support from the Australian National Health and Medical Research Council (NHMRC; 1016701, 1040978, 1086727, 1085191); NHMRC Independent Research Institute Infrastructure Support Scheme (IRIISS) (to WEHI); the Victorian State Government through the Victorian Cancer Agency and Operational Infrastructure Support; the National Breast Cancer Foundation (Australia); the Cancer Therapeutics CRC; Australian Cancer Research Foundation. G.J.L is supported by a NHMRC Research Fellowship (1078730); J.E.V. is supported by NHMRC Australia Fellowship (1037230).

Funda Meric-Bernstam - MD Anderson Moonshot funds, and Nellie B. Connally Breast Cancer Research Endowment

Helen Piwnica-Worms - This work was supported in part by the Cazalot Breast Cancer Model Resource, The Susan G. Komen Foundation and The Cancer Prevention and Research Institute of Texas (CPRIT) RP150148.

Jorge Reis-Filho - Research reported in this publication was supported in part by a grant from the Breast Cancer Research Foundation and a Cancer Center Support Grant of the National Institutes of Health/National Cancer Institute (Grant No. P30CA008748). The content is solely the responsibility of the authors and does not necessarily represent the official views of the National Institutes of Health".

Carol Sartorius - NIH grant CA140985,

Alana Welm - the Noreen Fraser Foundation, METAvivor Foundation, AACR Susan G Komen Career Catalyst award, DOD Breast Cancer Research Program grants W81XWH-08-1-0109 and BC112623, NIH/NCI grants 1R01CA166422 and 1R01CA173903

Max Wicha - R35: CA129765; RO1 CA101860, Komen for the Cure Promise Grant, Breast Cancer Research Foundation grant.

\section{References}

1. Allred DC, Wu Y, Mao S, Nagtegaal ID, Lee S, Perou CM, et al. Ductal carcinoma in situ and the emergence of diversity during breast cancer evolution. Clin Cancer Res. 2008; 14(2):370-378. [PubMed: 18223211]

2. Shipitsin M, Campbell LL, Argani P, Weremowicz S, Bloushtain-Qimron N, Yao J, et al. Molecular definition of breast tumor heterogeneity. Cancer Cell. 2007; 11(3):259-273. [PubMed: 17349583] 
3. Allred DC, Harvey JM, Berardo M, Clark GM. Prognostic and predictive factors in breast cancer by immunohistochemical analysis. Mod Pathol. 1998; 11(2):155-168. [PubMed: 9504686]

4. Sorlie T, Perou CM, Tibshirani R, Aas T, Geisler S, Johnsen H, et al. Gene expression patterns of breast carcinomas distinguish tumor subclasses with clinical implications. Proc Natl Acad Sci U S A. 2001; 98(19):10869-10874. [PubMed: 11553815]

5. Prat A, Parker JS, Karginova O, Fan C, Livasy C, Herschkowitz JI, et al. Phenotypic and molecular characterization of the claudin-low intrinsic subtype of breast cancer. Breast Cancer Res. 2010; 12(5):R68. [PubMed: 20813035]

6. Parker JS, Mullins M, Cheang MC, Leung S, Voduc D, Vickery T, et al. Supervised risk predictor of breast cancer based on intrinsic subtypes. J Clin Oncol. 2009; 27(8):1160-1167. [PubMed: 19204204]

7. Perou CM, Sorlie T, Eisen MB, van de Rijn M, Jeffrey SS, Rees CA, et al. Molecular portraits of human breast tumours. Nature. 2000; 406(6797):747-752. [PubMed: 10963602]

8. Hait WN. Anticancer drug development: the grand challenges. Nat Rev Drug Discov. 2010; 9(4): 253-254. [PubMed: 20369394]

9. Marusyk A, Polyak K. Tumor heterogeneity: causes and consequences. [Research Support, N.I.H., Extramural Research Support, Non-U.S. Gov't Research Support, U.S. Gov't, Non-P.H.S. Review]. Biochimica et biophysica acta. 2010; 1805(1):105-117. [PubMed: 19931353]

10. Park SY, Lee HE, Li H, Shipitsin M, Gelman R, Polyak K. Heterogeneity for stem cell-related markers according to tumor subtype and histologic stage in breast cancer. [Research Support, N.I.H., Extramural Research Support, Non-U.S. Gov't Research Support, U.S. Gov't, Non-P.H.S.]. Clinical cancer research : an official journal of the American Association for Cancer Research. 2010; 16(3):876-887. [PubMed: 20103682]

11. Burstein HJ, Temin S, Anderson H, Buchholz TA, Davidson NE, Gelmon KE, et al. Adjuvant endocrine therapy for women with hormone receptor-positive breast cancer: american society of clinical oncology clinical practice guideline focused update. [Practice Guideline]. Journal of clinical oncology : official journal of the American Society of Clinical Oncology. 2014; 32(21): 2255-2269. [PubMed: 24868023]

12. Ramakrishna N, Temin S, Chandarlapaty S, Crews JR, Davidson NE, Esteva FJ, et al. Recommendations on disease management for patients with advanced human epidermal growth factor receptor 2-positive breast cancer and brain metastases: American Society of Clinical Oncology clinical practice guideline. [Practice Guideline Research Support, Non-U.S. Gov't Review]. Journal of clinical oncology : official journal of the American Society of Clinical Oncology. 2014; 32(19):2100-2108. [PubMed: 24799487]

13. Telli ML, Timms KM, Reid J, Hennessy B, Mills GB, Jensen KC, et al. Homologous Recombination Deficiency (HRD) Score Predicts Response to Platinum-Containing Neoadjuvant Chemotherapy in Patients with Triple-Negative Breast Cancer. Clinical cancer research : an official journal of the American Association for Cancer Research. 2016; 22(15):3764-3773. [PubMed: 26957554]

14. Herschkowitz JI, Simin K, Weigman VJ, Mikaelian I, Usary J, Hu Z, et al. Identification of conserved gene expression features between murine mammary carcinoma models and human breast tumors. Genome Biol. 2007; 8(5):R76. [PubMed: 17493263]

15. Lim E, Vaillant F, Wu D, Forrest NC, Pal B, Hart AH, et al. Aberrant luminal progenitors as the candidate target population for basal tumor development in BRCA1 mutation carriers. Nat Med. 2009; 15(8):907-913. [PubMed: 19648928]

16. Li X, Lewis MT, Huang J, Gutierrez C, Osborne CK, Wu MF, et al. Intrinsic resistance of tumorigenic breast cancer cells to chemotherapy. [Research Support, N.I.H., Extramural Research Support, Non-U.S. Gov't Research Support, U.S. Gov't, Non-P.H.S.]. Journal of the National Cancer Institute. 2008; 100(9):672-679. [PubMed: 18445819]

17. Banerji S, Cibulskis K, Rangel-Escareno C, Brown KK, Carter SL, Frederick AM, et al. Sequence analysis of mutations and translocations across breast cancer subtypes. [Research Support, N.I.H., Extramural Research Support, Non-U.S. Gov't]. Nature. 2012; 486(7403):405-409. [PubMed: 22722202]

18. Curtis C, Shah SP, Chin SF, Turashvili G, Rueda OM, Dunning MJ, et al. The genomic and transcriptomic architecture of 2,000 breast tumours reveals novel subgroups. [Research Support, 
N.I.H., Extramural Research Support, Non-U.S. Gov't]. Nature. 2012; 486(7403):346-352. [PubMed: 22522925]

19. Network, T. C. G. A. Comprehensive molecular portraits of human breast tumours. [Research Support, N.I.H., Extramural Research Support, Non-U.S. Gov't Research Support, U.S. Gov't, Non-P.H.S.]. Nature. 2012; 490(7418):61-70. [PubMed: 23000897]

20. Shah SP, Roth A, Goya R, Oloumi A, Ha G, Zhao Y, et al. The clonal and mutational evolution spectrum of primary triple-negative breast cancers. [Research Support, N.I.H., Extramural Research Support, Non-U.S. Gov't Research Support, U.S. Gov't, Non-P.H.S.]. Nature. 2012; 486(7403):395-399. [PubMed: 22495314]

21. Stephens PJ, Tarpey PS, Davies H, Van Loo P, Greenman C, Wedge DC, et al. The landscape of cancer genes and mutational processes in breast cancer. [Research Support, N.I.H., Extramural Research Support, Non-U.S. Gov't]. Nature. 2012; 486(7403):400-404. [PubMed: 22722201]

22. Pereira B, Chin SF, Rueda OM, Vollan HK, Provenzano E, Bardwell HA, et al. Erratum: The somatic mutation profiles of 2,433 breast cancers refine their genomic and transcriptomic landscapes. Nature communications. 2016; 7:11908.

23. Pereira B, Chin SF, Rueda OM, Vollan HK, Provenzano E, Bardwell HA, et al. The somatic mutation profiles of 2,433 breast cancers refines their genomic and transcriptomic landscapes. Nature communications. 2016; 7:11479.

24. Xu H, Eirew P, Mullaly SC, Aparicio S. The omics of triple-negative breast cancers. [Review]. Clinical chemistry. 2014; 60(1):122-133. [PubMed: 24298072]

25. Lehmann BD, Jovanovic B, Chen X, Estrada MV, Johnson KN, Shyr Y, et al. Refinement of TripleNegative Breast Cancer Molecular Subtypes: Implications for Neoadjuvant Chemotherapy Selection. PLoS One. 2016; 11(6):e0157368. [PubMed: 27310713]

26. Le Du F, Eckhardt BL, Lim B, Litton JK, Moulder S, Meric-Bernstam F, et al. Is the future of personalized therapy in triple-negative breast cancer based on molecular subtype? [Research Support, N.I.H., Extramural Research Support, Non-U.S. Gov't Review]. Oncotarget. 2015; 6(15): 12890-12908. [PubMed: 25973541]

27. Burstein MD, Tsimelzon A, Poage GM, Covington KR, Contreras A, Fuqua SA, et al. Comprehensive genomic analysis identifies novel subtypes and targets of triple-negative breast cancer. [Research Support, N.I. H., Extramural Research Support, Non-U.S. Gov't]. Clin Cancer Res. 2015; 21(7):1688-1698. [PubMed: 25208879]

28. Abramson VG, Lehmann BD, Ballinger TJ, Pietenpol JA. Subtyping of triple-negative breast cancer: implications for therapy. [Research Support, N.I.H., Extramural Research Support, NonU.S. Gov't Review]. Cancer. 2015; 121(1):8-16. [PubMed: 25043972]

29. Prabhu JS, Korlimarla A, Desai K, Alexander A, Raghavan R, Anupama C, et al. A Majority of Low (1-10\%) ER Positive Breast Cancers Behave Like Hormone Receptor Negative Tumors. Journal of Cancer. 2014; 5(2):156-165. [PubMed: 24563670]

30. Hammond ME, Hayes DF, Dowsett M, Allred DC, Hagerty KL, Badve S, et al. American Society of Clinical Oncology/College of American Pathologists guideline recommendations for immunohistochemical testing of estrogen and progesterone receptors in breast cancer. Archives of pathology \& laboratory medicine. 2010; 134(6):907-922. [PubMed: 20524868]

31. Allott EH, Geradts J, Sun X, Cohen SM, Zirpoli GR, Khoury T, et al. Intratumoral heterogeneity as a source of discordance in breast cancer biomarker classification. Breast Cancer Res. 2016; 18(1): 68. [PubMed: 27349894]

32. Wolff AC, Hammond ME, Hicks DG, Dowsett M, McShane LM, Allison KH, et al. Recommendations for human epidermal growth factor receptor 2 testing in breast cancer: American Society of Clinical Oncology/College of American Pathologists clinical practice guideline update. [Practice Guideline]. Archives of pathology \& laboratory medicine. 2014; 138(2):241-256. [PubMed: 24099077]

33. Nowell PC. The clonal evolution of tumor cell populations. [Research Support, U.S. Gov't, P.H.S.]. Science. 1976; 194(4260):23-28. [PubMed: 959840]

34. De Luca F, Rotunno G, Salvianti F, Galardi F, Pestrin M, Gabellini S, et al. Mutational analysis of single circulating tumor cells by next generation sequencing in metastatic breast cancer. Oncotarget. 2016 
35. Martelotto LG, Ng CK, Piscuoglio S, Weigelt B, Reis-Filho JS. Breast cancer intratumor heterogeneity. [Research Support, Non-U.S. Gov't Review]. Breast Cancer Res. 2014; 16(3):210. [PubMed: 25928070]

36. Beca F, Polyak K. Intratumor Heterogeneity in Breast Cancer. Advances in experimental medicine and biology. 2016; 882:169-189. [PubMed: 26987535]

37. Ding L, Ellis MJ, Li S, Larson DE, Chen K, Wallis JW, et al. Genome remodelling in a basal-like breast cancer metastasis and xenograft. Nature. 2010; 464(7291):999-1005. [PubMed: 20393555]

38. Ha G, Roth A, Khattra J, Ho J, Yap D, Prentice LM, et al. TITAN: inference of copy number architectures in clonal cell populations from tumor whole-genome sequence data. [Research Support, Non-U.S. Gov't]. Genome research. 2014; 24(11):1881-1893. [PubMed: 25060187]

39. Nik-Zainal S, Van Loo P, Wedge DC, Alexandrov LB, Greenman CD, Lau KW, et al. The life history of 21 breast cancers. [Research Support, N.I.H., Extramural Research Support, Non-U.S. Gov't]. Cell. 2012; 149(5):994-1007. [PubMed: 22608083]

40. Roth A, Khattra J, Yap D, Wan A, Laks E, Biele J, et al. PyClone: statistical inference of clonal population structure in cancer. [Research Support, Non-U.S. Gov't]. Nature methods. 2014; 11(4): 396-398. [PubMed: 24633410]

41. Walter MJ, Shen D, Ding L, Shao J, Koboldt DC, Chen K, et al. Clonal architecture of secondary acute myeloid leukemia. [Research Support, N.I.H., Extramural Research Support, Non-U.S. Gov't]. The New England journal of medicine. 2012; 366(12):1090-1098. [PubMed: 22417201]

42. Baslan T, Kendall J, Rodgers L, Cox H, Riggs M, Stepansky A, et al. Genome-wide copy number analysis of single cells. [Research Support, Non-U.S. Gov't Research Support, U.S. Gov't, NonP.H.S.]. Nature protocols. 2012; 7(6):1024-1041. [PubMed: 22555242]

43. Baslan T, Kendall J, Rodgers L, Cox H, Riggs M, Stepansky A, et al. Corrigendum: Genome-wide copy number analysis of single cells. [Published Erratum]. Nature protocols. 2016; 11(3):616.

44. Eirew P, Steif A, Khattra J, Ha G, Yap D, Farahani H, et al. Dynamics of genomic clones in breast cancer patient xenografts at single-cell resolution. [Research Support, Non-U.S. Gov't]. Nature. 2015; 518(7539):422-426. [PubMed: 25470049]

45. Hou Y, Song L, Zhu P, Zhang B, Tao Y, Xu X, et al. Single-cell exome sequencing and monoclonal evolution of a JAK2-negative myeloproliferative neoplasm. [Research Support, Non-U.S. Gov't]. Cell. 2012; 148(5):873-885. [PubMed: 22385957]

46. Navin N, Kendall J, Troge J, Andrews P, Rodgers L, McIndoo J, et al. Tumour evolution inferred by single-cell sequencing. [Research Support, N.I.H., Extramural Research Support, Non-U.S. Gov't Research Support, U.S. Gov't, Non-P.H.S.]. Nature. 2011; 472(7341):90-94. [PubMed: 21399628]

47. Potter NE, Ermini L, Papaemmanuil E, Cazzaniga G, Vijayaraghavan G, Titley I, et al. Single-cell mutational profiling and clonal phylogeny in cancer. [Research Support, Non-U.S. Gov't]. Genome research. 2013; 23(12):2115-2125. [PubMed: 24056532]

48. Wang Y, Waters J, Leung ML, Unruh A, Roh W, Shi X, et al. Clonal evolution in breast cancer revealed by single nucleus genome sequencing. [Research Support, N.I.H., Extramural Research Support, Non-U.S. Gov't]. Nature. 2014; 512(7513):155-160. [PubMed: 25079324]

49. Shah SP, Morin RD, Khattra J, Prentice L, Pugh T, Burleigh A, et al. Mutational evolution in a lobular breast tumour profiled at single nucleotide resolution. Nature. 2009; 461(7265):809-813. [PubMed: 19812674]

50. Campbell PJ, Pleasance ED, Stephens PJ, Dicks E, Rance R, Goodhead I, et al. Subclonal phylogenetic structures in cancer revealed by ultra-deep sequencing. Proc Natl Acad Sci U S A. 2008; 105(35):13081-13086. [PubMed: 18723673]

51. Marusyk A, Tabassum DP, Altrock PM, Almendro V, Michor F, Polyak K. Non-cell-autonomous driving of tumour growth supports sub-clonal heterogeneity. [Research Support, N.I.H., Extramural Research Support, Non-U.S. Gov't Research Support, U.S. Gov't, Non-P.H.S.]. Nature. 2014; 514(7520):54-58. [PubMed: 25079331]

52. Beckhove P, Schutz F, Diel IJ, Solomayer EF, Bastert G, Foerster J, et al. Efficient engraftment of human primary breast cancer transplants in nonconditioned NOD/Scid mice. Int J Cancer. 2003; 105(4):444-453. [PubMed: 12712433] 
53. Visonneau S, Cesano A, Torosian MH, Miller EJ, Santoli D. Growth characteristics and metastatic properties of human breast cancer xenografts in immunodeficient mice. Am J Pathol. 1998; 152(5):1299-1311. [PubMed: 9588898]

54. Zhang X, Claerhout S, Prat A, Dobrolecki LE, Petrovic I, Lai Q, et al. A renewable tissue resource of phenotypically stable, biologically and ethnically diverse, patient-derived human breast cancer xenograft models. Cancer Res. 2013; 73(15):4885-4897. [PubMed: 23737486]

55. Fichtner I, Becker M, Zeisig R, Sommer A. In vivo models for endocrine-dependent breast carcinomas: special considerations of clinical relevance. Eur J Cancer. 2004; 40(6):845-851. [PubMed: 15120040]

56. McManus MJ, Welsch CW. DNA synthesis of benign human breast tumors in the untreated athymic "nude" mouse. An in vivo model to study hormonal influences on growth of human breast tissues. Cancer. 1980; 45(8):2160-2165. [PubMed: 7370957]

57. Murthy MS, Scanlon EF, Jelachich ML, Klipstein S, Goldschmidt RA. Growth and metastasis of human breast cancers in athymic nude mice. Clin Exp Metastasis. 1995; 13(1):3-15. [PubMed: 7820953]

58. Naundorf H, Fichtner I, Buttner B, Frege J. Establishment and characterization of a new human oestradiol- and progesterone-receptor-positive mammary carcinoma serially transplantable in nude mice. J Cancer Res Clin Oncol. 1992; 119(1):35-40. [PubMed: 1400563]

59. Noel A, Borcy V, Bracke M, Gilles C, Bernard J, Birembaut P, et al. Heterotransplantation of primary and established human tumour cells in nude mice. Anticancer Res. 1995; 15(1):1-7. [PubMed: 7733618]

60. Outzen HC, Custer RP. Growth of human normal and neoplastic mammary tissues in the cleared mammary fat pad of the nude mouse. Journal of the National Cancer Institute. 1975; 55(6):14611466. [PubMed: 1206764]

61. Rae-Venter B, Reid LM. Growth of human breast carcinomas in nude mice and subsequent establishment in tissue culture. Cancer Res. 1980; 40(1):95-100. [PubMed: 6243091]

62. Sakakibara T, Xu Y, Bumpers HL, Chen FA, Bankert RB, Arredondo MA, et al. Growth and metastasis of surgical specimens of human breast carcinomas in SCID mice. Cancer J Sci Am. 1996; 2(5):291-300. [PubMed: 9166547]

63. Sebesteny A, Taylor-Papadimitriou J, Ceriani R, Millis R, Schmitt C, Trevan D. Primary human breast carcinomas transplantable in the nude mouse. Journal of the National Cancer Institute. 1979; 63(6):1331-1337. [PubMed: 92586]

64. Sheffield LG, Welsch CW. Transplantation of human breast epithelia to mammary-gland-free fatpads of athymic nude mice: influence of mammotrophic hormones on growth of breast epithelia. Int J Cancer. 1988; 41(5):713-719. [PubMed: 3366492]

65. Shultz LD, Ishikawa F, Greiner DL. Humanized mice in translational biomedical research. [Research Support, N.I.H., Extramural Research Support, Non-U.S. Gov't Review]. Nat Rev Immunol. 2007; 7(2):118-130. [PubMed: 17259968]

66. Zhang X, Lewis MT. Establishment of Patient-Derived Xenograft (PDX) Models of Human Breast Cancer. Current Protocols in Mouse Biology. 2013; 3:21-29. [PubMed: 26069021]

67. Zhang H, Cohen AL, Krishnakumar S, Wapnir IL, Veeriah S, Deng G, et al. Patient-derived xenografts of triple-negative breast cancer reproduce molecular features of patient tumors and respond to mTOR inhibition. Breast Cancer Res. 2014; 16(2):R36. [PubMed: 24708766]

68. Marangoni E, Vincent-Salomon A, Auger N, Degeorges A, Assayag F, de Cremoux P, et al. A new model of patient tumor-derived breast cancer xenografts for preclinical assays. Clin Cancer Res. 2007; 13(13):3989-3998. [PubMed: 17606733]

69. Kabos P, Finlay-Schultz J, Li C, Kline E, Finlayson C, Wisell J, et al. Patient-derived luminal breast cancer xenografts retain hormone receptor heterogeneity and help define unique estrogendependent gene signatures. Breast Cancer Res Treat. 2012; 135(2):415-432. [PubMed: 22821401]

70. Al-Hajj M, Wicha MS, Benito-Hernandez A, Morrison SJ, Clarke MF. Prospective identification of tumorigenic breast cancer cells. Proc Natl Acad Sci U S A. 2003; 100(7):3983-3988. [PubMed: 12629218] 
71. DeRose YS, Wang G, Lin YC, Bernard PS, Buys SS, Ebbert MT, et al. Tumor grafts derived from women with breast cancer authentically reflect tumor pathology, growth, metastasis and disease outcomes. Nat Med. 2011; 17(11):1514-1520. [PubMed: 22019887]

72. DeRose YS, Gligorich KM, Wang G, Georgelas A, Bowman P, Courdy SJ, et al. Patient-derived models of human breast cancer: protocols for in vitro and in vivo applications in tumor biology and translational medicine. Curr Protoc Pharmacol, Chapter 14. 2013 Unit14 23.

73. Li S, Shen D, Shao J, Crowder R, Liu W, Prat A, et al. Endocrine-therapy-resistant ESR1 variants revealed by genomic characterization of breast-cancer-derived xenografts. Cell Rep. 2013; 4(6): 1116-1130. [PubMed: 24055055]

74. Vaillant F, Merino D, Lee L, Breslin K, Pal B, Ritchie ME, et al. Targeting BCL-2 with the BH3 mimetic ABT-199 in estrogen receptor-positive breast cancer. Cancer Cell. 2013; 24(1):120-129. [PubMed: 23845444]

75. Kuperwasser C, Chavarria T, Wu M, Magrane G, Gray JW, Carey L, et al. Reconstruction of functionally normal and malignant human breast tissues in mice. Proc Natl Acad Sci U S A. 2004; 101(14):4966-4971. [PubMed: 15051869]

76. Lewis, MT. Xenograft models of the normal and malignant human breast. In: Wang, X., editor. Translational Animal Models in Drug Discovery and Development. Sharjah: United Arab emirates: Bentham Science Publishers; 2012. p. 122-138.

77. Whittle JR, Lewis MT, Lindeman GJ, Visvader JE. Patient-derived xenograft models of breast cancer and their predictive power. [Research Support, N.I.H., Extramural Research Support, NonU.S. Gov't Review]. Breast Cancer Res. 2015; 17:17. [PubMed: 25849559]

78. Lum DH, Matsen C, Welm AL, Welm BE. Overview of human primary tumorgraft models: comparisons with traditional oncology preclinical models and the clinical relevance and utility of primary tumorgrafts in basic and translational oncology research. [Research Support, N.I.H., Extramural Research Support, Non-U.S. Gov't Research Support, U.S. Gov't, Non-P.H.S.]. Curr Protoc Pharmacol, Chapter 14. 2012 Unit 1422.

79. Hidalgo M, Amant F, Biankin AV, Budinska E, Byrne AT, Caldas C, et al. Patient-derived xenograft models: an emerging platform for translational cancer research. [Review]. Cancer Discov. 2014; 4(9):998-1013. [PubMed: 25185190]

80. Neve RM, Chin K, Fridlyand J, Yeh J, Baehner FL, Fevr T, et al. A collection of breast cancer cell lines for the study of functionally distinct cancer subtypes. Cancer Cell. 2006; 10(6):515-527. [PubMed: 17157791]

81. Hollestelle A, Nagel JH, Smid M, Lam S, Elstrodt F, Wasielewski M, et al. Distinct gene mutation profiles among luminal-type and basal-type breast cancer cell lines. Breast Cancer Res Treat. 2009

82. Chin K, DeVries S, Fridlyand J, Spellman PT, Roydasgupta R, Kuo WL, et al. Genomic and transcriptional aberrations linked to breast cancer pathophysiologies. Cancer Cell. 2006; 10(6): 529-541. [PubMed: 17157792]

83. Bonnefoi H, Potti A, Delorenzi M, Mauriac L, Campone M, Tubiana-Hulin M, et al. Validation of gene signatures that predict the response of breast cancer to neoadjuvant chemotherapy: a substudy of the EORTC 10994/BIG 00-01 clinical trial. Lancet Oncol. 2007; 8(12):1071-1078. [PubMed: 18024211]

84. Potti A, Dressman HK, Bild A, Riedel RF, Chan G, Sayer R, et al. Genomic signatures to guide the use of chemotherapeutics. Nat Med. 2006; 12(11):1294-1300. [PubMed: 17057710]

85. Salter KH, Acharya CR, Walters KS, Redman R, Anguiano A, Garman KS, et al. An integrated approach to the prediction of chemotherapeutic response in patients with breast cancer. PLoS One. 2008; 3(4):e1908. [PubMed: 18382681]

86. Liedtke C, Wang J, Tordai A, Symmans WF, Hortobagyi GN, Kiesel L, et al. Clinical evaluation of chemotherapy response predictors developed from breast cancer cell lines. Breast Cancer Res Treat. 2009

87. Wu M, Robinson MO. Human-in-mouse breast cancer model. Cell Cycle. 2009; 8(15):2317-2318. [PubMed: 19625762]

88. Rottenberg S, Pajic M, Jonkers J. Studying drug resistance using genetically engineered mouse models for breast cancer. [Research Support, Non-U.S. Gov't]. Methods in molecular biology. 2010; 596:33-45. [PubMed: 19949919] 
89. Cardiff RD. Validity of mouse mammary tumour models for human breast cancer: comparative pathology. Microsc Res Tech. 2001; 52(2):224-230. [PubMed: 11169869]

90. Kim JB, O'Hare MJ, Stein R. Models of breast cancer: is merging human and animal models the future? Breast Cancer Res. 2004; 6(1):22-30. [PubMed: 14680482]

91. Clarke R. Human breast cancer cell line xenografts as models of breast cancer. The immunobiologies of recipient mice and the characteristics of several tumorigenic cell lines. Breast Cancer Res Treat. 1996; 39(1):69-86. [PubMed: 8738607]

92. Kenny PA, Lee GY, Myers CA, Neve RM, Semeiks JR, Spellman PT, et al. The morphologies of breast cancer cell lines in three-dimensional assays correlate with their profiles of gene expression. Mol Oncol. 2007; 1(1):84-96. [PubMed: 18516279]

93. Weigelt B, Lo AT, Park CC, Gray JW, Bissell MJ. HER2 signaling pathway activation and response of breast cancer cells to HER2-targeting agents is dependent strongly on the 3D microenvironment. Breast Cancer Res Treat. 2009

94. Gillet JP, Calcagno AM, Varma S, Marino M, Green LJ, Vora MI, et al. Redefining the relevance of established cancer cell lines to the study of mechanisms of clinical anti-cancer drug resistance. Proc Natl Acad Sci U S A. 2011; 108(46):18708-18713. [PubMed: 22068913]

95. Johnson JI, Decker S, Zaharevitz D, Rubinstein LV, Venditti JM, Schepartz S, et al. Relationships between drug activity in NCI preclinical in vitro and in vivo models and early clinical trials. Br J Cancer. 2001; 84(10):1424-1431. [PubMed: 11355958]

96. Ellis LM, Fidler IJ. Finding the tumor copycat. Therapy fails, patients don't. Nat Med. 2010; 16(9): 974-975. [PubMed: 20823880]

97. Hampton OA, Den Hollander P, Miller CA, Delgado DA, Li J, Coarfa C, et al. A sequence-level map of chromosomal breakpoints in the MCF-7 breast cancer cell line yields insights into the evolution of a cancer genome. Genome Res. 2009; 19(2):167-177. [PubMed: 19056696]

98. Nugoli M, Chuchana P, Vendrell J, Orsetti B, Ursule L, Nguyen C, et al. Genetic variability in MCF-7 sublines: evidence of rapid genomic and RNA expression profile modifications. BMC Cancer. 2003; 3:13. [PubMed: 12713671]

99. du Manoir S, Orsetti B, Bras-Goncalves R, Nguyen TT, Lasorsa L, Boissiere F, et al. Breast tumor PDXs are genetically plastic and correspond to a subset of aggressive cancers prone to relapse. Mol Oncol. 2014; 8(2):431-443. [PubMed: 24394560]

100. Prat A, Perou CM. Deconstructing the molecular portraits of breast cancer. Mol Oncol. 2011; 5(1):5-23. [PubMed: 21147047]

101. Petrillo LA, Wolf DM, Kapoun AM, Wang NJ, Barczak A, Xiao Y, et al. Xenografts faithfully recapitulate breast cancer-specific gene expression patterns of parent primary breast tumors. Breast Cancer Res Treat. 2012; 135(3):913-922. [PubMed: 22941572]

102. Giuliano M, Herrera S, Christiny P, Shaw C, Creighton CJ, Mitchell T, et al. Circulating and disseminated tumor cells from breast cancer patient-derived xenograft-bearing mice as a novel model to study metastasis. [Research Support, N.I.H., Extramural Research Support, Non-U.S. Gov't]. Breast Cancer Res. 2015; 17:3. [PubMed: 25572662]

103. Powell E, Shao J, Yuan Y, Chen HC, Cai S, Echeverria GV, et al. p53 deficiency linked to B cell translocation gene 2 (BTG2) loss enhances metastatic potential by promoting tumor growth in primary and metastatic sites in patient-derived xenograft (PDX) models of triple-negative breast cancer. Breast Cancer Res. 2016; 18(1):13. [PubMed: 26818199]

104. Flanagan SP. 'Nude', a new hairless gene with pleiotropic effects in the mouse. Genet Res. 1966; 8(3):295-309. [PubMed: 5980117]

105. Kaushik A, Kelsoe G, Jaton JC. The nude mutation results in impaired primary antibody repertoire. Eur J Immunol. 1995; 25(2):631-634. [PubMed: 7875225]

106. Wortis HH, Nehlsen S, Owen JJ. Abnormal development of the thymus in "nude" mice. J Exp Med. 1971; 134(3 Pt 1):681-692. [PubMed: 15776569]

107. Kaestner KH, Knochel W, Martinez DE. Unified nomenclature for the winged helix/forkhead transcription factors. Genes Dev. 2000; 14(2):142-146. [PubMed: 10702024]

108. Nehls M, Pfeifer D, Schorpp M, Hedrich H, Boehm T. New member of the winged-helix protein family disrupted in mouse and rat nude mutations. Nature. 1994; 372(6501):103-107. [PubMed: 7969402] 
109. Osborne CK, Hobbs K, Clark GM. Effect of estrogens and antiestrogens on growth of human breast cancer cells in athymic nude mice. Cancer Res. 1985; 45(2):584-590. [PubMed: 3967234]

110. Seibert K, Shafie SM, Triche TJ, Whang-Peng JJ, O'Brien SJ, Toney JH, et al. Clonal variation of MCF-7 breast cancer cells in vitro and in athymic nude mice. Cancer Res. 1983; 43(5):22232239. [PubMed: 6831445]

111. Popnikolov NK, Yang J, Guzman RC, Swanson SM, Thordarson G, Collins G, et al. In vivo growth stimulation of collagen gel embedded normal human and mouse primary mammary epithelial cells. J Cell Physiol. 1995; 163(1):51-60. [PubMed: 7896900]

112. Soule HD, McGrath CM. Estrogen responsive proliferation of clonal human breast carcinoma cells in athymic mice. Cancer Lett. 1980; 10(2):177-189. [PubMed: 7459836]

113. McAuliffe PF, Evans KW, Akcakanat A, Chen K, Zheng X, Zhao H, et al. Correction: Ability to Generate Patient-Derived Breast Cancer Xenografts Is Enhanced in Chemoresistant Disease and Predicts Poor Patient Outcomes. [Published Erratum]. PLoS One. 2016; 11(3):e0151121. [PubMed: 26953790]

114. McAuliffe PF, Evans KW, Akcakanat A, Chen K, Zheng X, Zhao H, et al. Ability to Generate Patient-Derived Breast Cancer Xenografts Is Enhanced in Chemoresistant Disease and Predicts Poor Patient Outcomes. [Research Support, N.I.H., Extramural Research Support, Non-U.S. Gov't]. PLoS One. 2015; 10(9):e0136851. [PubMed: 26325287]

115. Mombaerts P, Iacomini J, Johnson RS, Herrup K, Tonegawa S, Papaioannou VE. RAG-1-deficient mice have no mature B and T lymphocytes. Cell. 1992; 68(5):869-877. [PubMed: 1547488]

116. Wunderlich M, Mizukawa B, Chou FS, Sexton C, Shrestha M, Saunthararajah Y, et al. AML cells are differentially sensitive to chemotherapy treatment in a human xenograft model. [Research Support, N.I.H., Extramural Research Support, U.S. Gov't, Non-P.H.S.]. Blood. 2013; 121(12):e90-e97. [PubMed: 23349390]

117. Bosma GC, Fried M, Custer RP, Carroll A, Gibson DM, Bosma MJ. Evidence of functional lymphocytes in some (leaky) scid mice. J Exp Med. 1988; 167(3):1016-1033. [PubMed: 3280724]

118. Bosma GC, Custer RP, Bosma MJ. A severe combined immunodeficiency mutation in the mouse. Nature. 1983; 301(5900):527-530. [PubMed: 6823332]

119. Blunt T, Finnie NJ, Taccioli GE, Smith GC, Demengeot J, Gottlieb TM, et al. Defective DNAdependent protein kinase activity is linked to $\mathrm{V}(\mathrm{D}) \mathrm{J}$ recombination and DNA repair defects associated with the murine scid mutation. Cell. 1995; 80(5):813-823. [PubMed: 7889575]

120. Nonoyama S, Smith FO, Bernstein ID, Ochs HD. Strain-dependent leakiness of mice with severe combined immune deficiency. J Immunol. 1993; 150(9):3817-3824. [PubMed: 8473734]

121. Custer RP, Bosma GC, Bosma MJ. Severe combined immunodeficiency (SCID) in the mouse. Pathology, reconstitution, neoplasms. [Research Support, Non-U.S. Gov't Research Support, U.S. Gov't, P.H.S.]. The American journal of pathology. 1985; 120(3):464-477. [PubMed: 2412448]

122. Christianson SW, Greiner DL, Schweitzer IB, Gott B, Beamer GL, Schweitzer PA, et al. Role of natural killer cells on engraftment of human lymphoid cells and on metastasis of human $\mathrm{T}$ lymphoblastoid leukemia cells in C57BL/6J-scid mice and in C57BL/6J-scid bg mice. Cell Immunol. 1996; 171(2):186-199. [PubMed: 8806787]

123. Greiner DL, Shultz LD, Yates J, Appel MC, Perdrizet G, Hesselton RM, et al. Improved engraftment of human spleen cells in NOD/LtSz-scid/scid mice as compared with C.B-17-scid/ scid mice. Am J Pathol. 1995; 146(4):888-902. [PubMed: 7717456]

124. Hudson WA, Li Q, Le C, Kersey JH. Xenotransplantation of human lymphoid malignancies is optimized in mice with multiple immunologic defects. Leukemia. 1998; 12(12):2029-2033. [PubMed: 9844934]

125. Dewan MZ, Terunuma H, Ahmed S, Ohba K, Takada M, Tanaka Y, et al. Natural killer cells in breast cancer cell growth and metastasis in SCID mice. Biomed Pharmacother. 2005; 59(Suppl 2):S375-S379. [PubMed: 16507413]

126. Roder J, Duwe A. The beige mutation in the mouse selectively impairs natural killer cell function. Nature. 1979; 278(5703):451-453. [PubMed: 313007] 
127. Xia Z, Taylor PR, Locklin RM, Gordon S, Cui Z, Triffitt JT. Innate immune response to human bone marrow fibroblastic cell implantation in CB17 scid/beige mice. J Cell Biochem. 2006; 98(4):966-980. [PubMed: 16795075]

128. Gouon-Evans V, Lin EY, Pollard JW. Requirement of macrophages and eosinophils and their cytokines/chemokines for mammary gland development. Breast Cancer Res. 2002; 4(4):155-164. [PubMed: 12100741]

129. Gouon-Evans V, Rothenberg ME, Pollard JW. Postnatal mammary gland development requires macrophages and eosinophils. Development. 2000; 127(11):2269-2282. [PubMed: 10804170]

130. Yang L, Huang J, Ren X, Gorska AE, Chytil A, Aakre M, et al. Abrogation of TGF beta signaling in mammary carcinomas recruits Gr-1+CD11b+ myeloid cells that promote metastasis. Cancer Cell. 2008; 13(1):23-35. [PubMed: 18167337]

131. Iyer V, Klebba I, McCready J, Arendt LM, Betancur-Boissel M, Wu MF, et al. Estrogen promotes ER-negative tumor growth and angiogenesis through mobilization of bone marrow-derived monocytes. Cancer Res. 2012; 72(11):2705-2713. [PubMed: 22467173]

132. Shultz LD, Schweitzer PA, Christianson SW, Gott B, Schweitzer IB, Tennent B, et al. Multiple defects in innate and adaptive immunologic function in NOD/LtSz-scid mice. J Immunol. 1995; 154(1):180-191. [PubMed: 7995938]

133. Pflumio F, Izac B, Katz A, Shultz LD, Vainchenker W, Coulombel L. Phenotype and function of human hematopoietic cells engrafting immune-deficient CB17-severe combined immunodeficiency mice and nonobese diabetic-severe combined immunodeficiency mice after transplantation of human cord blood mononuclear cells. Blood. 1996; 88(10):3731-3740. [PubMed: 8916937]

134. Cashman JD, Lapidot T, Wang JC, Doedens M, Shultz LD, Lansdorp P, et al. Kinetic evidence of the regeneration of multilineage hematopoiesis from primitive cells in normal human bone marrow transplanted into immunodeficient mice. Blood. 1997; 89(12):4307-4316. [PubMed: 9192753]

135. Sikora MJ, Cooper KL, Bahreini A, Luthra S, Wang G, Chandran UR, et al. Invasive lobular carcinoma cell lines are characterized by unique estrogen-mediated gene expression patterns and altered tamoxifen response. [Research Support, N.I.H., Extramural Research Support, Non-U.S. Gov't Research Support, U.S. Gov't, Non-P.H.S.]. Cancer Res. 2014; 74(5):1463-1474. [PubMed: 24425047]

136. Eyre R, Alferez DG, Clarke RB. J Mammary Gland Biol Neoplasia. 2016 (in press).

137. Shultz LD, Lyons BL, Burzenski LM, Gott B, Chen X, Chaleff S, et al. Human lymphoid and myeloid cell development in NOD/LtSz-scid IL2R gamma null mice engrafted with mobilized human hemopoietic stem cells. J Immunol. 2005; 174(10):6477-6489. [PubMed: 15879151]

138. Ito M, Hiramatsu H, Kobayashi K, Suzue K, Kawahata M, Hioki K, et al. NOD/SCID/gamma(c) (null) mouse: an excellent recipient mouse model for engraftment of human cells. Blood. 2002; 100(9):3175-3182. [PubMed: 12384415]

139. Oakes SR, Vaillant F, Lim E, Lee L, Breslin K, Feleppa F, et al. Sensitization of BCL-2expressing breast tumors to chemotherapy by the BH3 mimetic ABT-737. [Research Support, Non-U.S. Gov't]. Proceedings of the National Academy of Sciences of the United States of America. 2012; 109(8):2766-2771. [PubMed: 21768359]

140. Nolan E, Vaillant F, Branstetter D, Pal B, Giner G, Whitehead L, et al. RANK ligand as a potential target for breast cancer prevention in BRCA1-mutation carriers. Nat Med. 2016; 22(8): 933-939. [PubMed: 27322743]

141. Richard E, Grellety T, Velasco V, MacGrogan G, Bonnefoi H, Iggo R. The mammary ducts create a favourable microenvironment for xenografting of luminal and molecular apocrine breast tumours. The Journal of pathology. 2016

142. McDermott SP, Eppert K, Lechman ER, Doedens M, Dick JE. Comparison of human cord blood engraftment between immunocompromised mouse strains. [Comparative Study Research Support, Non-U.S. Gov't]. Blood. 2010; 116(2):193-200. [PubMed: 20404133]

143. Bondarenko G, Ugolkov A, Rohan S, Kulesza P, Dubrovskyi O, Gursel D, et al. Patient-Derived Tumor Xenografts Are Susceptible to Formation of Human Lymphocytic Tumors. [Research 
Support, N.I.H., Extramural Research Support, Non-U.S. Gov't]. Neoplasia. 2015; 17(9):735741. [PubMed: 26476081]

144. Wetterauer C, Vlajnic T, Schuler J, Gsponer JR, Thalmann GN, Cecchini M, et al. Early development of human lymphomas in a prostate cancer xenograft program using triple knock-out immunocompromised mice. [Research Support, Non-U.S. Gov't]. The Prostate. 2015; 75(6):585592. [PubMed: 25585936]

145. Moon HG, Oh K, Lee J, Lee M, Kim JY, Yoo TK, et al. Prognostic and functional importance of the engraftment-associated genes in the patient-derived xenograft models of triple-negative breast cancers. [Research Support, Non-U.S. Gov't]. Breast Cancer Res Treat. 2015; 154(1):13-22. [PubMed: 26438141]

146. Gullino PM. Considerations on the preneoplastic lesions of the mammary gland. Am J Pathol. 1977; 89(2):413-430. [PubMed: 200144]

147. Brem SS, Jensen HM, Gullino PM. Angiogenesis as a marker of preneoplastic lesions of the human breast. Cancer. 1978; 41:239-244. [PubMed: 626933]

148. Bogden AE, Haskell PM, LePage DJ, Kelton DE, Cobb WR, Esber HJ. Growth of human tumor xenografts implanted under the renal capsule of normal immunocompetent mice. Exp Cell Biol. 1979; 47(4):281-293. [PubMed: 467773]

149. Bogden, AE., Kelton, DE., Cobb, WB., Esber, HJ. A rapid screening method for testing chemotherapeutic agents against human tumor xenografts. In: Houchens, Ovejera, editors. Symposium on the use of athymic (nude) mice in cancer research, 1978; New York. p. 231

150. Aamdal S, Fodstad O, Nesland JM, Pihl A. Characteristics of human tumour xenografts transplanted under the renal capsule of immunocompetent mice. Br J Cancer. 1985; 51(3):347356. [PubMed: 3970811]

151. Eirew P, Stingl J, Raouf A, Turashvili G, Aparicio S, Emerman JT, et al. A method for quantifying normal human mammary epithelial stem cells with in vivo regenerative ability. Nat Med. 2008; 14(12):1384-1389. [PubMed: 19029987]

152. DeOme KB, Faulkin LJJ, Bern H. Development of mammary tumors from hyperplastic alveolar nodules transplanted into gland-free mammary fat pads of female $\mathrm{C} 3 \mathrm{H}$ mice. Cancer Res. 1958; 19:515-520.

153. Behbod F, Kittrell FS, LaMarca H, Edwards D, Kerbawy S, Heestand JC, et al. An intraductal human-in-mouse transplantation model mimics the subtypes of ductal carcinoma in situ. Breast Cancer Res. 2009; 11(5):R66. [PubMed: 19735549]

154. Sflomos G, Dormoy V, Metsalu T, Jeitziner R, Battista L, Scabia V, et al. A Preclinical Model for ERalpha-Positive Breast Cancer Points to the Epithelial Microenvironment as Determinant of Luminal Phenotype and Hormone Response. [Research Support, Non-U.S. Gov't]. Cancer Cell. 2016; 29(3):407-422. [PubMed: 26947176]

155. Kang Y, Siegel PM, Shu W, Drobnjak M, Kakonen SM, Cordon-Cardo C, et al. A multigenic program mediating breast cancer metastasis to bone. Cancer Cell. 2003; 3(6):537-549. [PubMed: 12842083]

156. Palmieri D, Smith QR, Lockman PR, Bronder J, Gril B, Chambers AF, et al. Brain metastases of breast cancer. Breast Dis. 2006; 26:139-147. [PubMed: 17473372]

157. Bos PD, Zhang XH, Nadal C, Shu W, Gomis RR, Nguyen DX, et al. Genes that mediate breast cancer metastasis to the brain. Nature. 2009; 459(7249):1005-1009. [PubMed: 19421193]

158. Minn AJ, Gupta GP, Siegel PM, Bos PD, Shu W, Giri DD, et al. Genes that mediate breast cancer metastasis to lung. Nature. 2005; 436(7050):518-524. [PubMed: 16049480]

159. Murphy P, Alexander P, Senior PV, Fleming J, Kirkham N, Taylor I. Mechanisms of organ selective tumour growth by bloodborne cancer cells. Br J Cancer. 1988; 57(1):19-31. [PubMed: 3348947]

160. Yi B, Williams PJ, Niewolna M, Wang Y, Yoneda T. Tumor-derived platelet-derived growth factor-BB plays a critical role in osteosclerotic bone metastasis in an animal model of human breast cancer. Cancer Res. 2002; 62(3):917-923. [PubMed: 11830552]

161. Lam P, Yang W, Amemiya Y, Kahn H, Yee A, Holloway C, et al. A human bone NOD/SCID mouse model to distinguish metastatic potential in primary breast cancers. Cancer Biol Ther. 2009; 8(11):1010-1017. [PubMed: 19398888] 
162. Faulkin LJ Jr, Deome KB. Regulation of growth and spacing of gland elements in the mammary fat pad of the C3H mouse. Journal of the National Cancer Institute. 1960; 24:953-969. [PubMed: 13821714]

163. Deome KB, Faulkin LJ Jr, Bern HA, Blair PB. Development of mammary tumors from hyperplastic alveolar nodules transplanted into gland-free mammary fat pads of female $\mathrm{C} 3 \mathrm{H}$ mice. Cancer Res. 1959; 19(5):515-520. [PubMed: 13663040]

164. Bailey MJ, Gazet JC, Peckham MJ. Human breast-cancer xenografts in immune-suppressed mice. Br J Cancer. 1980; 42(4):524-529. [PubMed: 6254552]

165. Levin-Allerhand JA, Sokol K, Smith JD. Safe and effective method for chronic 17beta-estradiol administration to mice. [Comparative Study Research Support, Non-U.S. Gov't]. Contemporary topics in laboratory animal science / American Association for Laboratory Animal Science. 2003; 42(6):33-35.

166. Welsch CW, Swim EL, McManus MJ, White AC, McGrath CM. Estrogen induced growth of human breast cancer cells (MCF-7) in athymic nude mice is enhanced by secretions from a transplantable pituitary tumor. [Research Support, Non-U.S. Gov't Research Support, U.S. Gov't, P.H.S.]. Cancer letters. 1981; 14(3):309-316. [PubMed: 7332907]

167. Cottu P, Marangoni E, Assayag F, de Cremoux P, Vincent-Salomon A, Guyader C, et al. Modeling of response to endocrine therapy in a panel of human luminal breast cancer xenografts. [Research Support, Non-U.S. Gov't]. Breast Cancer Res Treat. 2012; 133(2):595-606. [PubMed: 22002565]

168. Hatem R, El Botty R, Chateau-Joubert S, Servely JL, Labiod D, de Plater L, et al. Targeting mTOR pathway inhibits tumor growth in different molecular subtypes of triple-negative breast cancers. Oncotarget. 2016

169. Gupta PB, Kuperwasser C. Contributions of estrogen to ER-negative breast tumor growth. J Steroid Biochem Mol Biol. 2006; 102(1-5):71-78. [PubMed: 17049443]

170. Gupta PB, Proia D, Cingoz O, Weremowicz J, Naber SP, Weinberg RA, et al. Systemic stromal effects of estrogen promote the growth of estrogen receptor-negative cancers. Cancer Res. 2007; 67(5):2062-2071. [PubMed: 17332335]

171. Pequeux C, Raymond-Letron I, Blacher S, Boudou F, Adlanmerini M, Fouque MJ, et al. Stromal estrogen receptor-alpha promotes tumor growth by normalizing an increased angiogenesis. [Research Support, Non-U.S. Gov't]. Cancer Res. 2012; 72(12):3010-3019. [PubMed: 22523036]

172. Pece S, Tosoni D, Confalonieri S, Mazzarol G, Vecchi M, Ronzoni S, et al. Biological and molecular heterogeneity of breast cancers correlates with their cancer stem cell content. [Research Support, Non-U.S. Gov't]. Cell. 2010; 140(1):62-73. [PubMed: 20074520]

173. Charafe-Jauffret E, Ginestier C, Bertucci F, Cabaud O, Wicinski J, Finetti P, et al. ALDH1positive cancer stem cells predict engraftment of primary breast tumors and are governed by a common stem cell program. [Research Support, Non-U.S. Gov't]. Cancer Res. 2013; 73(24): 7290-7300. [PubMed: 24142344]

174. Rong S, Oskarsson M, Faletto D, Tsarfaty I, Resau JH, Nakamura T, et al. Tumorigenesis induced by coexpression of human hepatocyte growth factor and the human met protooncogene leads to high levels of expression of the ligand and receptor. Cell Growth Differ. 1993; 4(7):563-569. [PubMed: 8398896]

175. Utama FE, LeBaron MJ, Neilson LM, Sultan AS, Parlow AF, Wagner KU, et al. Human prolactin receptors are insensitive to mouse prolactin: implications for xenotransplant modeling of human breast cancer in mice. J Endocrinol. 2006; 188(3):589-601. [PubMed: 16522738]

176. Rong S, Bodescot M, Blair D, Dunn J, Nakamura T, Mizuno K, et al. Tumorigenicity of the met proto-oncogene and the gene for hepatocyte growth factor. Mol Cell Biol. 1992; 12(11):51525158. [PubMed: 1406687]

177. Kaur H, Mao S, Shah S, Gorski DH, Krawetz SA, Sloane BF, et al. Next-generation sequencing: a powerful tool for the discovery of molecular markers in breast ductal carcinoma in situ. Expert Rev Mol Diagn. 2013; 13(2):151-165. [PubMed: 23477556]

178. Miller FR. Xenograft models of premalignant breast disease. J Mammary Gland Biol Neoplasia. 2000; 5(4):379-391. [PubMed: 14973383] 
179. Holland PA, Knox WF, Potten CS, Howell A, Anderson E, Baildam AD, et al. Assessment of hormone dependence of comedo ductal carcinoma in situ of the breast. Journal of the National Cancer Institute. 1997; 89(14):1059-1065. [PubMed: 9230888]

180. Warnberg F, White D, Anderson E, Knox F, Clarke RB, Morris J, et al. Effect of a farnesyl transferase inhibitor (R115777) on ductal carcinoma in situ of the breast in a human xenograft model and on breast and ovarian cancer cell growth in vitro and in vivo. Breast Cancer Res. 2006; 8(2):R21. [PubMed: 16611371]

181. Miller FR, Soule HD, Tait L, Pauley RJ, Wolman SR, Dawson PJ, et al. Xenograft model of progressive human proliferative breast disease. Journal of the National Cancer Institute. 1993; 85(21):1725-1732. [PubMed: 8411256]

182. Dawson PJ, Wolman SR, Tait L, Heppner GH, Miller FR. MCF10AT: a model for the evolution of cancer from proliferative breast disease. Am J Pathol. 1996; 148(1):313-319. [PubMed: 8546221]

183. Hu M, Yao J, Carroll DK, Weremowicz S, Chen H, Carrasco D, et al. Regulation of in situ to invasive breast carcinoma transition. Cancer Cell. 2008; 13(5):394-406. [PubMed: 18455123]

184. Forozan F, Veldman R, Ammerman CA, Parsa NZ, Kallioniemi A, Kallioniemi OP, et al. Molecular cytogenetic analysis of 11 new breast cancer cell lines. Br J Cancer. 1999; 81(8): 1328-1334. [PubMed: 10604729]

185. Gupta PB KC. Disease models of breast cancer. [Review]. Drug Discovery Today: Disease Models. 2004; 1(1):9-16.

186. Proia DA, Kuperwasser C. Reconstruction of human mammary tissues in a mouse model. Nat Protoc. 2006; 1(1):206-214. [PubMed: 17406234]

187. Klopp AH, Gupta A, Spaeth E, Andreeff M, Marini F 3rd. Concise review: Dissecting a discrepancy in the literature: do mesenchymal stem cells support or suppress tumor growth? [Research Support, N.I.H., Extramural Research Support, Non-U.S. Gov't Review]. Stem Cells. 2011; 29(1):11-19. [PubMed: 21280155]

188. Klopp AH, Lacerda L, Gupta A, Debeb BG, Solley T, Li L, et al. Mesenchymal stem cells promote mammosphere formation and decrease E-cadherin in normal and malignant breast cells. [Research Support, N.I.H., Extramural Research Support, Non-U.S. Gov't]. PLoS One. 2010; 5(8):e12180. [PubMed: 20808935]

189. Karnoub AE, Dash AB, Vo AP, Sullivan A, Brooks MW, Bell GW, et al. Mesenchymal stem cells within tumour stroma promote breast cancer metastasis. Nature. 2007; 449(7162):557-563. [PubMed: 17914389]

190. Liu S, Ginestier C, Ou SJ, Clouthier SG, Patel SH, Monville F, et al. Breast cancer stem cells are regulated by mesenchymal stem cells through cytokine networks. [Research Support, N.I.H., Extramural Research Support, Non-U.S. Gov't]. Cancer Res. 2011; 71(2):614-624. [PubMed: 21224357]

191. Smyth MJ, Dunn GP, Schreiber RD. Cancer immunosurveillance and immunoediting: the roles of immunity in suppressing tumor development and shaping tumor immunogenicity. [Research Support, N.I.H., Extramural Research Support, Non-U.S. Gov't Review]. Adv Immunol. 2006; 90:1-50. [PubMed: 16730260]

192. Condeelis J, Pollard JW. Macrophages: obligate partners for tumor cell migration, invasion, and metastasis. [Research Support, N.I.H., Extramural Research Support, Non-U.S. Gov't Review]. Cell. 2006; 124(2):263-266. [PubMed: 16439202]

193. DeNardo DG, Andreu P, Coussens LM. Interactions between lymphocytes and myeloid cells regulate pro- versus anti-tumor immunity. [Research Support, N.I.H., Extramural Research Support, Non-U.S. Gov't Research Support, U.S. Gov't, Non-P.H.S. Review]. Cancer Metastasis Rev. 2010; 29(2):309-316. [PubMed: 20405169]

194. Mantovani A, Sica A. Macrophages, innate immunity and cancer: balance, tolerance, and diversity. [Review]. Curr Opin Immunol. 2010; 22(2):231-237. [PubMed: 20144856]

195. Wyckoff JB, Wang Y, Lin EY, Li JF, Goswami S, Stanley ER, et al. Direct visualization of macrophage-assisted tumor cell intravasation in mammary tumors. [Research Support, N.I.H., Extramural]. Cancer Res. 2007; 67(6):2649-2656. [PubMed: 17363585] 
196. Mantovani A, Sica A, Allavena P, Garlanda C, Locati M. Tumor-associated macrophages and the related myeloid-derived suppressor cells as a paradigm of the diversity of macrophage activation. [Research Support, Non-U.S. Gov't Review]. Hum Immunol. 2009; 70(5):325-330. [PubMed: 19236898]

197. Knutson KL, Disis ML, Salazar LG. CD4 regulatory T cells in human cancer pathogenesis. [Research Support, N.I.H., Extramural Review]. Cancer Immunol Immunother. 2007; 56(3):271285. [PubMed: 16819631]

198. Hughes PE, Caenepeel S, Wu LC. Targeted Therapy and Checkpoint Immunotherapy Combinations for the Treatment of Cancer. [Review]. Trends Immunol. 2016; 37(7):462-476. [PubMed: 27216414]

199. Postow MA, Callahan MK, Wolchok JD. Immune Checkpoint Blockade in Cancer Therapy. [Review]. J Clin Oncol. 2015; 33(17):1974-1982. [PubMed: 25605845]

200. Rakhra K, Bachireddy P, Zabuawala T, Zeiser R, Xu L, Kopelman A, et al. CD4(+) T cells contribute to the remodeling of the microenvironment required for sustained tumor regression upon oncogene inactivation. [Comment Research Support, N.I.H., Extramural Research Support, Non-U.S. Gov't]. Cancer Cell. 2010; 18(5):485-498. [PubMed: 21035406]

201. Mosier DE, Gulizia RJ, Baird SM, Wilson DB. Transfer of a functional human immune system to mice with severe combined immunodeficiency. Nature. 1988; 335(6187):256-259. [PubMed: 2970594]

202. Wege AK, Ernst W, Eckl J, Frankenberger B, Vollmann-Zwerenz A, Mannel DN, et al. Humanized tumor mice--a new model to study and manipulate the immune response in advanced cancer therapy. [Research Support, Non-U.S. Gov't]. Int J Cancer. 2011; 129(9):2194-2206. [PubMed: 21544806]

203. Sanmamed MF, Chester C, Melero I, Kohrt H. Defining the optimal murine models to investigate immune checkpoint blockers and their combination with other immunotherapies. [Review]. Ann Oncol. 2016; 27(7):1190-1198. [PubMed: 26912558]

204. Holzapfel BM, Wagner F, Thibaudeau L, Levesque JP, Hutmacher DW. Concise review: humanized models of tumor immunology in the 21 st century: convergence of cancer research and tissue engineering. [Review]. Stem Cells. 2015; 33(6):1696-1704. [PubMed: 25694194]

205. Zhou Q, Facciponte J, Jin M, Shen Q, Lin Q. Humanized NOD-SCID IL2rg-/- mice as a preclinical model for cancer research and its potential use for individualized cancer therapies. [Review]. Cancer Lett. 2014; 344(1):13-19. [PubMed: 24513265]

206. Brehm MA, Shultz LD, Luban J, Greiner DL. Overcoming current limitations in humanized mouse research. [Research Support, N.I.H., Extramural Research Support, Non-U.S. Gov't Review]. J Infect Dis. 2013; 208(Suppl 2):S125-S130. [PubMed: 24151318]

207. Vargo-Gogola T. Putting the brakes on breast cancer: therapeutic opportunities to bring cancer stem cells and the tumor microenvironment to a screeching halt. [Editorial Introductory]. Curr Drug Targets. 2010; 11(9):1041-1042. [PubMed: 20545615]

208. Shumway NM, Ibrahim N, Ponniah S, Peoples GE, Murray JL. Therapeutic breast cancer vaccines: a new strategy for early-stage disease. [Review]. BioDrugs. 2009; 23(5):277-287. [PubMed: 19754218]

209. DeNardo DG, Brennan DJ, Rexhepaj E, Ruffell B, Shiao SL, Madden SF, et al. Leukocyte complexity predicts breast cancer survival and functionally regulates response to chemotherapy. [Research Support, N.I.H., Extramural Research Support, Non-U.S. Gov't Research Support, U.S. Gov't, Non-P.H.S.]. Cancer Discov. 2011; 1(1):54-67. [PubMed: 22039576]

210. Bedognetti D, Maccalli C, Bader SB, Marincola FM, Seliger B. Checkpoint Inhibitors and Their Application in Breast Cancer. [Review]. Breast Care (Basel). 2016; 11(2):108-115. [PubMed: 27239172]

211. Garcia S, Freitas AA. Humanized mice: current states and perspectives. [Review]. Immunology letters. 2012; 146(1-2):1-7. [PubMed: 22507217]

212. Rongvaux A, Willinger T, Martinek J, Strowig T, Gearty SV, Teichmann LL, et al. Development and function of human innate immune cells in a humanized mouse model. [Research Support, N.I.H., Extramural Research Support, Non-U.S. Gov't]. Nature biotechnology. 2014; 32(4):364372. 
213. Bertotti A, Migliardi G, Galimi F, Sassi F, Torti D, Isella C, et al. A molecularly annotated platform of patient-derived xenografts ("xenopatients") identifies HER2 as an effective therapeutic target in cetuximab-resistant colorectal cancer. [Research Support, Non-U.S. Gov't]. Cancer Discov. 2011; 1(6):508-523. [PubMed: 22586653]

214. Gao H, Korn JM, Ferretti S, Monahan JE, Wang Y, Singh M, et al. High-throughput screening using patient-derived tumor xenografts to predict clinical trial drug response. Nat Med. 2015; 21(11):1318-1325. [PubMed: 26479923] 


\section{Key Unanswered Questions}

1. To what extent can PDX models be used as patient "avatars" in preclinical evaluation of experimental therapeutics?

2. Can PDX-based "-omics" studies be used to develop predictive signatures and to identify key resistance mechanisms?

3. Under what circumstances does the lack of an intact immune system influence the usefulness of PDX models, and can this be overcome? 


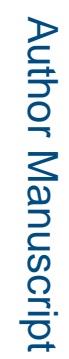

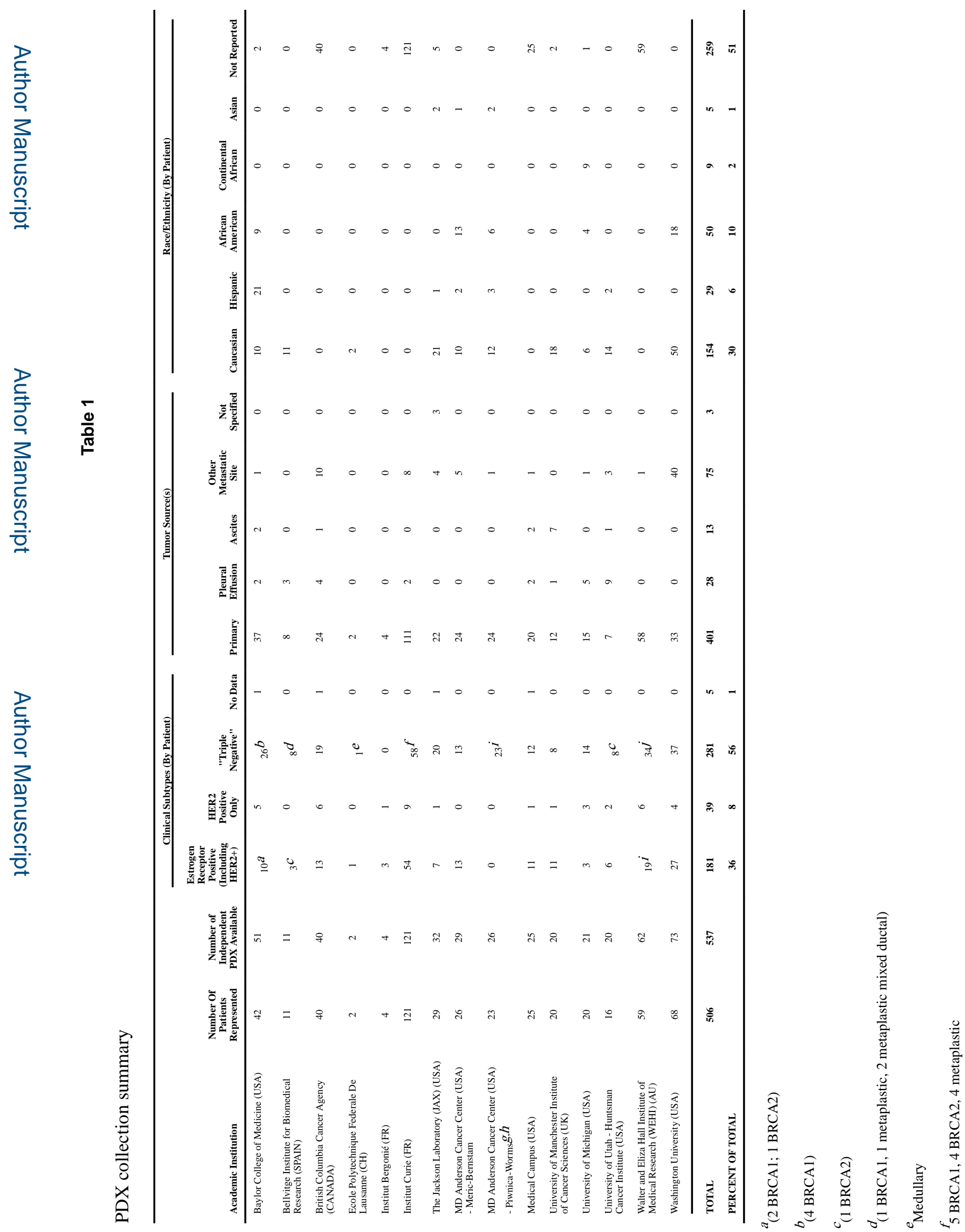




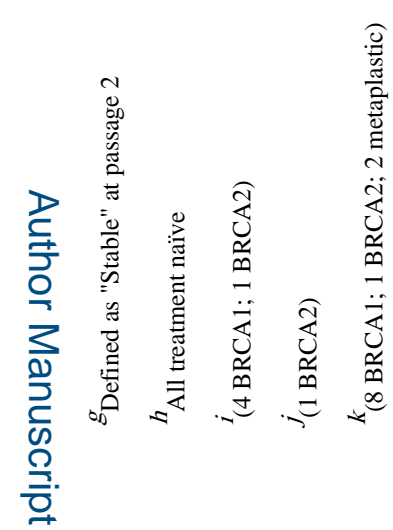

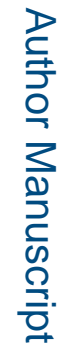

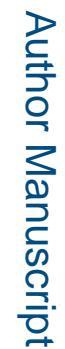

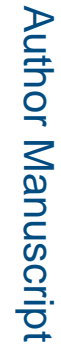

Cancer Metastasis Rev. Author manuscript; available in PMC 2017 December 01. 


\section{Table 2}

\section{Contact Information for PDX Collections}

\begin{tabular}{|c|c|}
\hline Academic Institution & Contact Name and E-mail \\
\hline Baylor College of Medicine (USA) & $\begin{array}{l}\text { Michael Lewis (mtlewis@bcm.edu) } \\
\text { Lacey Dobrolecki (dobrolec@bcm.edu) }\end{array}$ \\
\hline Bellvitge Institute for Biomedical Research (SPAIN) & Eva Gonzalez-Suarez (egsuarez@idibell.cat) \\
\hline British Columbia Cancer Agency (CANADA) & Samuel Aparicio (saparicio@bccrc.ca) \\
\hline Ecole Polytechnique Federale De Lausanne $(\mathrm{CH})$ & Cathrin Brisken (cathrin.brisken@epfl.ch) \\
\hline Institut Bergonié (FR) & Richard Iggo (r.iggo@bordeaux.unicancer.fr) \\
\hline Institut Curie (FR) & Elisabetta Marangoni (elisabetta.marangoni@curie.fr) \\
\hline The Jackson Laboratory (JAX) (USA) & $\begin{array}{l}\text { Carol Bult (Carol.Bult@jax.org) } \\
\text { Susie Airhart (Susie.Airhart@jax.org) }\end{array}$ \\
\hline MD Anderson Cancer Center (USA) -Meric-Bernstam & Funda Meric-Bernstam (fmeric@mdanderson.org) \\
\hline MD Anderson Cancer Center (USA) -Piwnica-Worms & Helen Piwnica-Worms (hpiwnica-worms@mdanderson.org) \\
\hline University of Colorado Anschutz Medical Campus (USA) & $\begin{array}{l}\text { Carol Sartorius (Carol.Sartorius@ ucdenver.edu) } \\
\text { Peter Kabos (Peter.Kabos@ ucdenver.edu) }\end{array}$ \\
\hline University of Manchester Institute of Cancer Sciences (UK) & $\begin{array}{l}\text { Robert Clarke (Robert.Clarke@ manchester.ac.uk) } \\
\text { Denes Alferez (denis.alferez@ manchester.ac.uk) }\end{array}$ \\
\hline University of Michigan (USA) & Max Wicha (mwicha@med.umich.edu) \\
\hline University of Utah -Huntsman Cancer Institute (USA) & Alana Welm (Alana.Welm@hci.utah.edu) \\
\hline Walter and Eliza Hall Institute of Medical Research (WEHI) (AU) & $\begin{array}{l}\text { Geoffrey Lindeman (lindeman@wehi.edu.au) } \\
\text { Jane Visvader (visvader@wehi.edu.au) }\end{array}$ \\
\hline Washington University (USA) & Shunqiang Li (shunqiangli@wustl.edu) \\
\hline
\end{tabular}



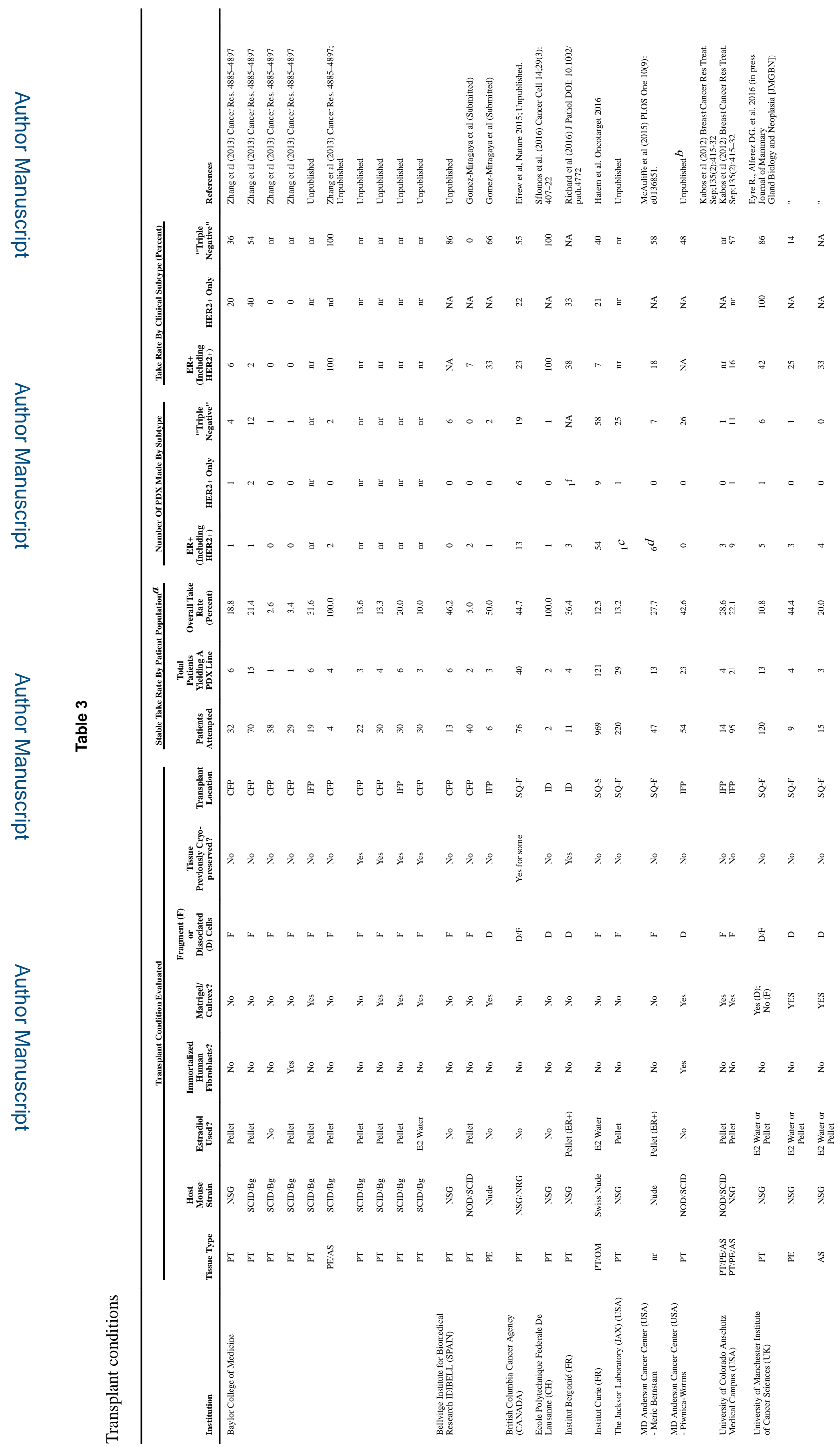


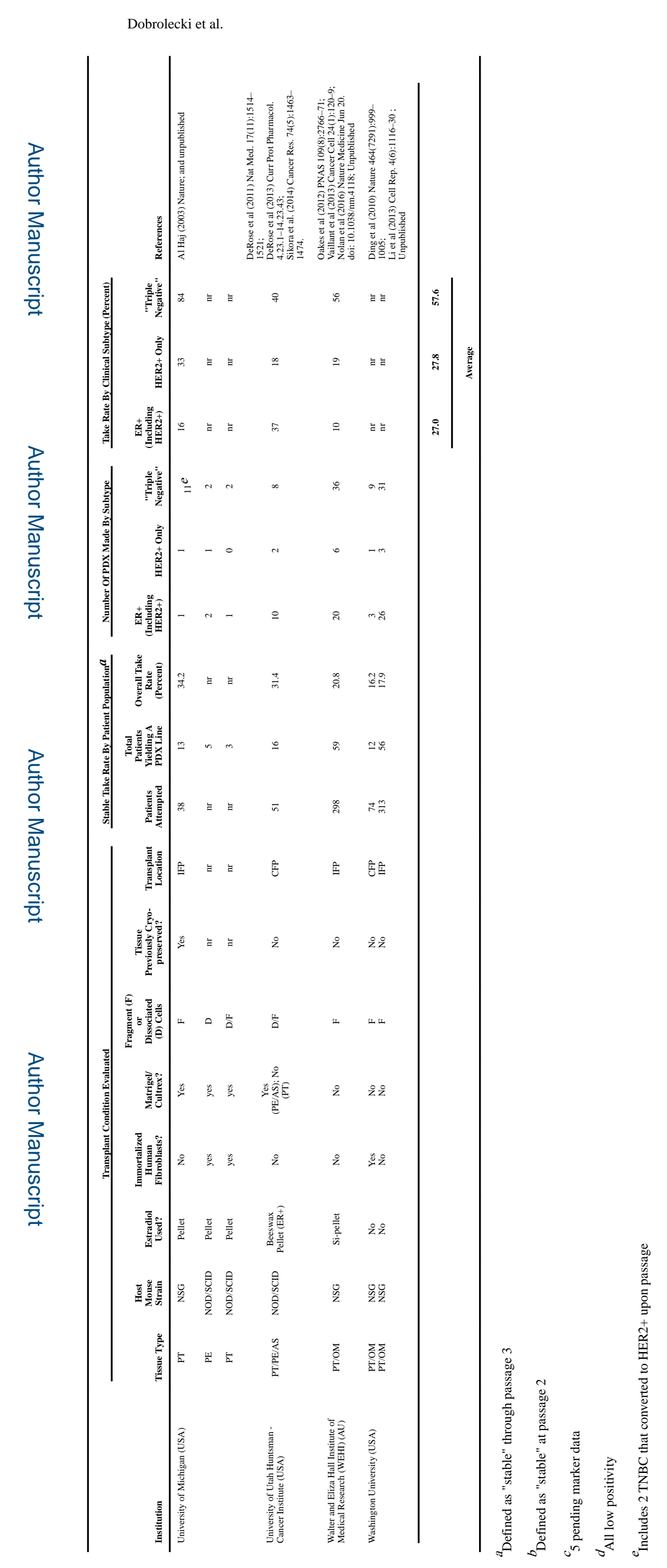




\section{Table 4}

Host Mouse Strains Used By Insititution

\begin{tabular}{|c|c|c|c|c|}
\hline Institution & $\begin{array}{l}\text { Host Mouse } \\
\text { Strain } \\
\text { Abbreviation }\end{array}$ & Full Strain Designation & Vendor & $\begin{array}{c}\text { Stock } \\
\text { Number }\end{array}$ \\
\hline Baylor College of Medicine & $\begin{array}{c}\mathrm{NSG} \\
\mathrm{SCID} / \mathrm{Bg}\end{array}$ & $\begin{array}{l}\text { NOD.Cg-Prkdc }{ }^{\text {scid }} \mathrm{Il} \mathrm{rg}^{\mathrm{tm} 1 \mathrm{~W}_{\mathrm{jl}} / \mathrm{SzJ}} \\
\text { CB17.Cg-Prkdc }{ }^{\text {scid }} \mathrm{Lyst}^{\mathrm{tg}-\mathrm{J}} / \mathrm{Crl}\end{array}$ & $\begin{array}{l}\text { JAX } \\
\text { CR }\end{array}$ & $\begin{array}{c}005557 \\
250\end{array}$ \\
\hline $\begin{array}{l}\text { Bellvitge Institute for Biomedical } \\
\text { Research IDIBELL (SPAIN) }\end{array}$ & $\begin{array}{l}\text { NSG } \\
\text { NOD/SCID } \\
\text { Nude }\end{array}$ & $\begin{array}{l}\text { NOD.Cg-Prkdc }{ }^{\text {scid }} I 12 \mathrm{rg}^{\mathrm{tm} 1 \mathrm{~W} \mathrm{j}} / \mathrm{SzJ} \\
\text { NOD.CB17-Prkde } \\
\text { Athymic Nude - Foxn } 1^{\text {nu }}\end{array}$ & $\begin{array}{l}\text { JAX via CR } \\
\text { JAX via CR } \\
\text { Harlan/Envigo }\end{array}$ & $\begin{array}{l}005557 \\
001303\end{array}$ \\
\hline $\begin{array}{l}\text { British Columbia Cancer Agency } \\
\text { (CANADA) }\end{array}$ & $\begin{array}{l}\text { NSG } \\
\text { NRG }\end{array}$ & $\begin{array}{l}\text { NOD.Cg-Prkdc }{ }^{\text {scid }} \mathrm{Il} 2 \mathrm{rg}^{\mathrm{tm} 1 \mathrm{~W} \mathrm{~W} l} / \mathrm{SzJ} \\
\text { NOD.Cg-Rag } 1^{\text {tmIMom }} I 12 \mathrm{rg}^{\mathrm{gtml} / \mathrm{Wj} / \mathrm{SzJ}}\end{array}$ & $\begin{array}{l}\text { JAX } \\
\text { JAX }\end{array}$ & $\begin{array}{l}005557 \\
007799\end{array}$ \\
\hline $\begin{array}{l}\text { Ecole Polytechnique Federale De } \\
\text { Lausanne (SW) }\end{array}$ & NSG & NOD.Cg-Prkdc ${ }^{\text {scid }} I 12 \mathrm{rg}^{\mathrm{tm} 1 \mathrm{Wj}_{\mathrm{j}} / \mathrm{SzJ}}$ & JAX & 005557 \\
\hline Institut Bergonié (FR) & NSG & NOD.Cg-Prkdc ${ }^{\text {scid }} \mathrm{Il} 2 \mathrm{rg}^{\mathrm{tm} 1 \mathrm{~W}_{\mathrm{jl}} / \mathrm{SzJ}}$ & JAX; bred in house & 005557 \\
\hline Institut Curie (FR) & Swiss Nude & Crl:NU(Ico)-Foxn1nu & CR & \\
\hline The Jackson Laboratory (JAX) (USA) & NSG & NOD.Cg-Prkdc ${ }^{\text {scid }} I 12 \mathrm{rg}^{\mathrm{tm} 1 \mathrm{Wj}_{\mathrm{jl}} / \mathrm{SzJ}}$ & JAX & 005557 \\
\hline $\begin{array}{l}\text { MD Anderson Cancer Center (USA) } \\
\text { - Meric Bernstam }\end{array}$ & Nude & Athymic Nude - Foxn $1^{\text {nu }}$ & MDACC Colony & NA \\
\hline $\begin{array}{l}\text { MD Anderson Cancer Center (USA) } \\
\text { - Piwnica-Worms }\end{array}$ & NOD/SCID & NOD.CB17-Prkde ${ }^{\text {scid }} / \mathrm{NcrCrl}$ & CR & 394 \\
\hline $\begin{array}{l}\text { University of Colorado Anschutz } \\
\text { Medical Campus (USA) }\end{array}$ & $\begin{array}{l}\text { NOD/SCID } \\
\text { NSG }\end{array}$ & $\begin{array}{l}\text { NOD.CB17-Prkdc } c^{\text {scid } / J} \\
\text { NOD.Cg-Prkdc } \\
\text { scid } I 12 \mathrm{rg}^{\mathrm{tm} 1 \mathrm{w}_{\mathrm{jl}} / \mathrm{SzJ}}\end{array}$ & $\begin{array}{c}\text { JAX } \\
\text { JAX; bred in house }\end{array}$ & $\begin{array}{l}001303 \\
005557\end{array}$ \\
\hline $\begin{array}{l}\text { University of Manchester Institute } \\
\text { of Cancer Sciences (UK) }\end{array}$ & NSG & 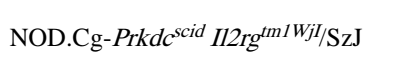 & JAX via $\mathrm{CR}$ & 005557 \\
\hline University of Michigan (USA) & $\begin{array}{c}\text { NSG } \\
\text { NOD/SCID }\end{array}$ & $\begin{array}{l}\text { NOD.CB17-Prkdcescid/J } \\
\text { NOD.Cg-Prkdc }{ }^{\text {scid }} I 12 \mathrm{rg}^{\mathrm{tm} 1 \mathrm{w}_{\mathrm{j}} \mathrm{l} / \mathrm{SzJ}}\end{array}$ & JAX; bred in house & $\begin{array}{l}005557 ; \\
001303\end{array}$ \\
\hline $\begin{array}{l}\text { University of Utah Huntsman - } \\
\text { Cancer Institute (USA) }\end{array}$ & NOD/SCID & NOD.CB17-Prkdc ${ }^{\text {scid/J }}$ & JAX & 001303 \\
\hline $\begin{array}{l}\text { Walter and Eliza Hall Institute of } \\
\text { Medical Research (WEHI) (AU) }\end{array}$ & NSG & NOD.Cg-Prkdc ${ }^{\text {scid }} I 12 \mathrm{rg}^{\mathrm{tm} 1 \mathrm{Wjl}_{\mathrm{j}} / \mathrm{SzJ}}$ & JAX; bred in house & 005557 \\
\hline Washington University (USA) & NSG & NOD.Cg-Prkdc ${ }^{\text {scid }} I 12 \mathrm{rg}^{\mathrm{tm} 1 \mathrm{Wj}_{\mathrm{j}} / \mathrm{SzJ}}$ & JAX & 005557 \\
\hline
\end{tabular}

